\title{
Avian Stress-Related Transcriptome and Selenotranscriptome: Role during Exposure to Heavy Metals and Heat Stress
}

\author{
Isidoros Seremelis ${ }^{1}$, Georgios P. Danezis ${ }^{1}{ }^{\mathbb{C}}$, Athanasios C. Pappas ${ }^{2}$, Evangelos Zoidis ${ }^{2, *}{ }^{\mathbb{C}}$ \\ and Kostas Fegeros 2 \\ 1 Chemistry Laboratory, Department of Food Science and Human Nutrition, Agricultural University of \\ Athens, 75 Iera Odos, 11855 Athens, Greece \\ 2 Department of Nutritional Physiology and Feeding, Faculty of Animal Science, Agricultural University of \\ Athens, 75 Iera Odos, 11855 Athens, Greece \\ * Correspondence: ezoidis@aua.gr; Tel.: +30-210-529-4415; Fax: +30-210-529-4413
}

Received: 10 June 2019; Accepted: 4 July 2019; Published: 10 July 2019

\begin{abstract}
Selenium, through incorporation into selenoproteins, is one of the key elements of the antioxidant system. Over the past few years there has been increased interest in exploring those molecular mechanisms in chicken, responsible for the development of this protection system. In more detail, $\mathrm{Cd} / \mathrm{Pb}$ poisoning and heat stress increase oxidation, mRNA levels of inflammatory proteins, and apoptotic proteins. Selenium seems to enhance the antioxidant status and alleviates these effects via upregulation of antioxidant proteins and other molecular effects. In this review, we analyze avian transcriptome key elements with particular emphasis on interactions with heavy metals and on relation to heat stress.
\end{abstract}

Keywords: Animal health; heat stress; heavy metals; selenium; selenoprotein; selenotranscriptome

\section{Introduction}

Selenium (Se) is characterized as a vital nutrient for animals and humans [1-3]. In the form of selenocystein (Sec), Se is integrated into selenoproteins to participate in various organism and cellular functions $[4,5]$. The main characteristic of all selenoproteins, is the presence of Sec in their peptides [6-8]. A stem-loop structure named selenocysteine insertion sequence (SECIS) is responsible for the decoding of a stop codon UGA to Sec (U) [9]. In mammalian genomes, integration of Se in selenoprotein requires the existence of SECIS. On the other hand, dietary Se deficiency, in diverse species, has been implicated in various diseases. In chicken, Se deficiency (SD) is characterized by the appearance of pendulous ventral part of the neck region giving a soft feel on palpation [10]. Also, $\mathrm{SD}$ results in loss of appetite, swollen legs, uncoordinated movement, poor feathering, and poor growth [11]. The Se shortage symptoms may appear in broiler chicks utilizing unsupplemented diets [12-14].

Cadmium (Cd) is a heavy metal and extremely toxic. It is accumulated into birds' organs mainly through the feed and on elevated concentrations can cause acute or chronic poisoning [15]. One of $\mathrm{Cd}$ toxicity mechanisms is the nitric oxide $(\mathrm{NO})$ overproduction and the expression of inducible $\mathrm{NO}$ synthase (iNOS) which governs NO synthesis. In splenic lymphocytes of chicks, exposure to Cd elevates the activity of NO and iNOS. Cadmium harms the liver, kidney, nerves, bones, and other organs [16]. In chicken, $\mathrm{Cd}$ exposure can cause altered behavioral responses and decreased egg production [17]. Specifically, it has been found that Cd could cause autophagy in chicken pancreas and alter the concentration of trace elements in kidney [18-20]. Additionally, the overproduction of $\mathrm{NO}$ affects Bcl-2, p53 and other genes, stimulating the release of cytochrome c (Cyt-c) and thereafter 
apoptosis [21]. As in the chicken, kidney of rabbits is the target organ of Cd toxicity. In rabbits, Cd is accumulated in various organs such as liver, kidney, and lung, impairing the functions of these organs [22,23]. Furthermore, reduction of cell antioxidant capacity and cell apoptosis is induced by $\mathrm{Cd}$ poisoning [24,25]. Also, exposure to Cd could lead in renal dysfunction [26]. It has been showed that $\mathrm{Cd}$, in sublethal concentration, has notably changed the levels of glycogen in kidneys of silver carp (Hypophthalmichthys molitrix) and triggered kidney damage [27,28].

Lead $(\mathrm{Pb})$ is another extremely toxic heavy metal that is broadly distributed in nature due to human activities. Lead can seep into the environment via various ways, including sewage discharges and burning of fossil fuels [29]. It has been reported, that vegetables may contaminate with $\mathrm{Pb}$ through burning of municipal waste and by emissions from industry. In leafy vegetables the accumulation of $\mathrm{Pb}$, is directly related to atmospheric $\mathrm{Pb}$ through absorption from leaves [30,31]. It is recognized, that $\mathrm{Pb}$ has toxic effects on several organs and systems in whole organism including central nervous system, blood system, heart, and kidney [32]. Furthermore, Pb exposure targets immune organs. Lead can impact the humoral immune function of organisms. It decreases the host's resistance to several pathogen infections. According to duration of $\mathrm{Pb}$ exposure and dose, it may be capable of reducing serum immunoglobulin levels [33]. It seemed that $\mathrm{T}$ lymphocytes are the most sensitive to the hazardous effects of $\mathrm{Pb}$. Further, Pb interferes with the TH1/TH2 lymphocytes balance [34], causing immune dysfunction triggered by inflammation [28]. Additionally, Xing et al. showed that $\mathrm{Pb}$ alters heat shock proteins (HSP) and cytokines mRNA expression and thus decreased immune function in chicken neutrophils [35]. Similar effects of $\mathrm{Pb}$ have been reported in several other avian species [36]. In detail, Gasparik et al. reported that $\mathrm{Pb}$ in pheasants is accumulated in kidneys, livers, pectoral muscles, eggs and ovaries, and reduced egg hatching rate, fertilization rate, and egg weight [37]. Also, Butkauskas and Sruiga showed that $\mathrm{Pb}$ was hazardous for fertility, hatchability, and reproductive success of Japanese quails [38]. Lead poisoning also affects heat shock proteins expression. Huang et al. demonstrated that $\mathrm{Pb}$ poisoning raises mRNA expressions of HSP27, HSP40, HSP60, HSP70, and HSP90 in the chicken testes. However, mRNA expression of HSP40 was the lowest in the Pb group and it was found about 24 times higher compared to the control group. These outcomes indicate that $\mathrm{Pb}$ toxicity results in higher mRNA expressions of HSPs [36].

Heavy metals are extremely poisonous for avian species. They cause dysfunctions in many organs and alter expression levels of many inflammation factors and antioxidative agents such as selenoproteins. In the later part of this review, we discuss in detail the effects of $\mathrm{Cd} / \mathrm{Pb}$ toxicity on avian transcriptome and the benefit of Se supplementation.

\section{Avian Transcriptome Response to Cadmium Toxicity and the Benefits of Selenium Supplementation}

\subsection{Inflammation Transcripts, Apoptotic Factors and Selenotranscriptome}

The predominant mediators of inflammation, cytokines, play a critical role in the inflammatory response induced by $\mathrm{Cd}$ exposure and other various environmental challenges in living organisms. Some studies have demonstrated that immune cells inflammatory response is closely related to the expression of inflammatory cytokines. TNF- $\alpha$ is the most important cytokine, activating neutrophils and lymphocytes, promoting the synthesis and release of other cytokines [39]. On the other hand, as a pro-inflammatory factor, the main function of iNOS in inflammatory neutrophils is the induction of NO production. Nitric oxide is synthesized under inflammatory conditions and takes part in immunoregulation [40,41]. Li-li Liu et al. demonstrated that $\mathrm{Cd}$ exposure of broiler cerebrum significantly raised $i N O S$ mRNA levels, $\mathrm{Cd}$ accumulation and NO production. Furthermore, $\mathrm{Cd}$ induced brain damage by adjusting iNOS-NO system changes [42].

It has been reported that $\mathrm{Cd}$ stimulation causes the expression of ICAM-1 via NF- $\mathrm{kB}$ activation in cerebrovascular endothelial cells similar to findings by Liu et al. [42]. Moreover, Låg $\mathrm{M}$ et al. have shown that the mRNA expression levels of IL-1 $\beta$ and TNF- $\alpha$ were reduced after exposure to Cd in lung cells of rats [43]. Furthermore, in another study, exposure to Cd increased mRNA expression of 
$I L-1 B$ while decreased $I L-17, I L-10, I L-4, I L-2$, and IFN- $\gamma$ in chicken splenic lymphocytes indicating an impact on immune responses. Supplementation with Se decreased $\mathrm{Cd}$ toxicity and in addition the mRNA expression levels of IL-17, IL-10, IL-2, IL-4, and IFN- $\gamma$ were higher than in the Cd alone treated group. However, the mRNA expression levels were not as high as in the Se alone treated group and the control group. Expression levels of mRNA of $I L-2$ were also higher in $\mathrm{Cd}$ and Se treated group than in Cd group. Additionally, in respect to the control group, the mRNA levels of IL-10 and IL-4 in chicken splenic lymphocytes were decreased dramatically due to Cd toxicity [44].

Moreover, Cd exposure could trigger immune cells to raise the mRNA expression of $I L-10$ and $I L-1 B$. At gene level, the altered gene expression regulation of cytokines induced the raise of IL- 4 and suppression of IFN- $\gamma$ production. Cadmium could influence the immune inflammation of neutrophils by modifying the regulation of cytokine expression as it turned out via the suppression of IL-17 production, the raise of IL- 4 release and the production of proinflammatory cytokines IL-1B, TNR- $\alpha$, IFN- $\gamma$, and IL-10. Also, Cd moderately induced the pro-inflammatory cytokines NF- $\kappa B$, iNOS, TNF- $\alpha$, COX-2, and PGE2. Furthermore, inflammation caused by $\mathrm{Cd}$ raised iNOS activity and NO production. Analogous results were demonstrated in the levels of NF-kB protein expression [45,46].

The key step for enabling downstream caspases, a family of protease enzymes playing essential roles in programmed cell death and inflammation, is the activation of Bak, a member of the proapoptotic Bcl-2 family, at the mitochondria. This has a crucial role in the regulation of apoptosis under chronic endoplasmatic reticulum stress (ERS). The role of ERS in inflammation and stress is not unilateral, ERS can be triggered by a variety of inflammatory factors, and many inflammatory diseases are associated with ERS. Similarly to previous reports on Cd toxicity and ERS, Chen et al. showed that Cd induces high expression of TNF- $\alpha$, IL-1b, IL-4, and IL-10 in peripheral blood neutrophils of broiler, acting as strong inducer of ERS and activating ER pathways, one of which is ATF6 cleavage [46]. When Cd triggers ERS, the apoptosis pathway is conducted by the ATF6 branch. Higher apoptotic cells populations were found in the $\mathrm{Cd}$ group compared to the control group. Also, the mRNA expression of caspase-12 in the Cd-induced chicken peripheral blood neutrophils model group was significantly higher than that in the control group. The results in the protein expression levels of caspase- 12 also illustrates that it is an important molecule, which initiates apoptosis selectively in response to ERS [46]. Furthermore, Chen et al. proposed that in the lack of apoptosis, the mRNA levels of caspase-9, GRP78, and caspase- 3 increased significantly while levels of $C a M$ and $B c l-x L$ decreased in the peripheral blood neutrophils of chicken in the $\mathrm{Cd}$ treatment group [46].

On the other hand, in hens liver, Cd toxicity caused significant increase of $I L-1 \beta, T N F-\alpha, C O X-2$, PTGES, and NF- $\kappa B$ mRNA levels while similarly, in hens serum, TNF- $\alpha$, and $I L-1 b$ were significantly increased [47]. Recently, a study by $C$ hen et al. showed that $C d$ exposure caused deregulation of miRNA-33-AMPK axis, further suppressed AKT/mTOR and HSP70-NF-KB/JNK signaling pathway and triggered BNIP3-dependent autophagy in chicken spleen [48]. Moreover, another study showed that $C d$ toxicity increased mRNA expression of caspase-3, Cyt-c, caspase-9, Bax, p53, and protein levels of caspase-3, Bax, and Cyt-c in liver of chicken. However, $\mathrm{Cd}$ toxicity reduced Bcl-2 protein and mRNA levels. These findings pointed that $\mathrm{Cd}$ induced apoptosis in chicken hepatocytes by the NO-mediated mitochondrial-dependent pathway and that $\mathrm{Cd}$-triggered apoptosis was mediated by the pro-apoptotic genes Bax, p53, and Bcl-2 [45].

Messenger-RNA expression of inflammatory cytokines plays a crucial role in inflammatory response. Under inflammatory conditions due to $\mathrm{Cd}$ exposure, NO levels and inflammatory cytokines are increased in avian tissues. Also, $\mathrm{Cd}$ toxicity induces strongly ERS. In addition, $\mathrm{Cd}$ toxicity induces apoptosis on chicken liver and neutrophils via Bak activation and triggers BNIP3-dependent autophagy on chicken neutrophils. Some ways on how Se supplementation may alleviate Cd toxicity are proposed.

\subsection{Selenium Supplementation}

There is little information about possible interactions of Se and $\mathrm{Cd}$ in mRNA expression of inflammation factors and selenoprotein genes. A study on Se/Cd treated chicks showed that Se 
co-administration with $C d$ alleviated the increase of COX-2, NF- $\kappa B, P T G E S$, and TNF- $\alpha$ mRNA levels caused by $\mathrm{Cd}$ in chicken kidneys. The mRNA levels of $N F-\kappa B$ and $T N F-\alpha$ slightly increased in $\mathrm{Se} / \mathrm{Cd}$ treated group in relation to control group but PTGES and COX-2 mRNA levels were not influenced [28]. Cadmium toxicity also induced energy metabolism disorders and mitochondrial damage and Se supplementation reduced mRNA expression of autophagy-related genes (Atg5, LC3-I, LC3-II, Beclin 1, dynein) caused by Cd treatment [49].

Also apoptosis and the mRNA level of Bak, p53, caspase-3, caspase-9, and Cyt-c increased significantly, and $B c l-2, B c l-x l$, and $C a M$ decreased in chicken splenic lymphocytes of $C d$ treatment groups. Furthermore, Amantana et al. showed that $\mathrm{Cd}$ exposure decreased induction of the promoter of selenoprotein $\mathrm{W}$ in rat myoblast and glial cells, which indicates that Cd targets some selenoproteins [50]. Cadmium decreased the expression of selenoprotein S, selenoprotein $\mathrm{T}$, selenoprotein $\mathrm{N}$, and selenoprotein $\mathrm{K}$ which are located in the endoplasmic reticulum. Moreover, the protection of Se may be related to the regulation of selenoproteins in chicken lymphocytes [51]. Selenoprotein $\mathrm{W}$ has essential role in redox regulation during induction of $\mathrm{Ca}^{2+}$ leakage in muscles [52]. As a result, selenoproteins may play major role in Cd toxicity process as well as in Se antagonistic function and are an important link between $\mathrm{Cd}$ and Se. These studies indicated that $\mathrm{Cd}$ treatment influenced the expression of selenoprotein genes, which may be targets of Cd toxicity. They show correlations between most of selenoproteins. Hence these selenoproteins function similarly in Se antagonism of $\mathrm{Cd}$ [53]. It was shown that $\mathrm{Cd}$ can reduce the expression levels of selenoprotein $\mathrm{N},-\mathrm{T},-\mathrm{K}$, and $-\mathrm{S}$ resided in ER and that Se protection property may be related to the regulation of selenoproteins [51]. On the other hand, another study on Cd exposure and Se co-administration showed that the levels of mRNA of GPX1 and TRXR1 were obviously lower in the Cd group compared with other groups. However, the $\mathrm{Cd} / \mathrm{Se}$ co-treatment significantly attenuated this decrease. Selenium supplementation alone with Cd treatment significantly increased the mRNA of GPX1 and TRXR1, similar to the immunoblotting results of GPX1 and TRXR1 [54].

In a study examining $\mathrm{Cd}$ exposure and chicken's kidney selenotranscritome regulation, there was a significant difference between the control group and Se-treated group in the mRNA levels of all 25 selenoprotein genes (selenoprotein $\mathrm{T}$, selenoprotein $\mathrm{N}$, selenoprotein $\mathrm{W}$, selenoprotein $\mathrm{K}$, Selenoprotein $\mathrm{U}$, selenoprotein $\mathrm{S}$, selenoprotein $\mathrm{O}$, selenoprotein $\mathrm{M}$, selenoprotein $\mathrm{I}$, selenoprotein $\mathrm{H}$, selenoprotein 15, selenoprotein Pb, SPS2, Sepp1, Sepx1, DIO3, DIO2, DIO1, GPX4, GPX3, GPX2, GPX1, TXNRD3, TXNRD2, and TXNRD1) [28]. Among the control group and Cd-treated group there was a crucial difference of mRNA of selenoprotein $W$, selenoprotein $U$, selenoprotein $T$, selenoprotein $S$, selenoprotein $\mathrm{Pb}$, selenoprotein $\mathrm{O}$, selenoprotein $\mathrm{N}$, selenoprotein $\mathrm{K}$, DIO3, GPX3, and GPX2 levels, but not in the mRNA expression levels of another 14 selenoprotein genes (selenoprotein 15, selenoprotein M, selenoprotein I, selenoprotein H, Sepp1, Sepx1, SPS2, DIO2, DIO1, GPX4, GPX1). In the group with Se/Cd treatment, the mRNA expression levels of selenoprotein $\mathrm{W}$, selenoprotein $\mathrm{U}$, selenoprotein $\mathrm{T}$, GPX3, and GPX2 alleviated, while the amount of alleviation was minor than that in the group with Cd treatment. The expression levels of selenoprotein $\mathrm{N}$, selenoprotein $\mathrm{K}$, selenoprotein $\mathrm{S}$, selenoprotein $\mathrm{O}$, selenoprotein $\mathrm{M}$, selenoprotein $\mathrm{I}$, selenoprotein $\mathrm{H}$, selenoprotein 15, selenoprotein $\mathrm{Pb}$, Sepx1, Sepp1, SPS2, DIO3, DIO2, DIO1, TXNRD3, TXNRD2, TXNRD1, GPX4, and GPX1 were not affected [28,55]. Additionally, treatment with Se through the reduction of MDA levels and the increase of Se-dependent antioxidant enzymes activities in chicken kidney tissues protected them from Cd toxicity $[28,56]$.

Apart from the studies mentioned above, Se protection mechanism against Cd toxicity is based on antioxidant proteins. Also, in another study, Se ameliorated Cd-induced oxidative stress through regulation of mRNA levels of GPX4 and selenoprotein P [57]. However, Se supplementation, decreased mRNA levels of proapoptotic proteins caspase-3, caspase-9, p53, Bax and Cyt-c. Moreover, mRNA levels of $\mathrm{Bcl}-2$ raised when concurrently supplemented Se and Cd in chicken nutrition [45]. 


\section{Avian Transcriptome Response to Lead Toxicity and the Benefits of Selenium Supplementation}

\section{Inflammatory Response}

Under chemical or noxious physical stimuli, one of the most important indicators of tissue damage is inflammation. The NF- $\mathrm{kB}$ signaling pathway has a significant role in inflammation regulation via the transcription of diverse target genes, including iNOS, COX-2, and TNF- $\alpha$. Regarding COX-2 and iNOS, they are significant enzymes that mediate processes of inflammation [58]. iNOS influences the lung inflammatory response through regulation of chemokine synthesis [59]. Moreover, TNF- $\alpha$ is known as a pro-inflammatory cytokine which may participate in the nonalcoholic fatty liver disease initiation [60]. Activation of NF- $\mathrm{KB}$ within endothelial cells constitutes a critical step in the rheumatoid arthritis pathogenesis of experimental models [61]. Pro-inflammatory response can be increased by $\mathrm{Pb}$. Furthermore, $\mathrm{Pb}$ decreases cell function in macrophages, possibly by enhancing TNF- $\alpha$ release and oxidative damage [62]. Cadmium-induced inflammatory reaction was weakened by Se, which was interceded, at least in part, by COX-2, iNOS, and TNF- $\alpha$ expression down-regulation, through the NF- $\mathrm{KB}$ activation suppression. Therefore, a defensive role of Se is indicated regarding Cd-induced inflammatory response [42].

Selenium could as well antagonize $\mathrm{Pb}$-induced damage on inflammatory cytokines gene expression in chickens' peripheral blood lymphocytes [63]. Chicken testes is the target organ where $\mathrm{Pb}$ accumulates and induces inflammation injury [64]. Also, $\mathrm{Pb}$ induced apoptosis in chicken testes. Jiao et al. reported that $\mathrm{Pb}$ toxicity raised MDA content; decreased GSH content; and decreased SOD, GPX and GST activities in chicken bursa of Fabricius [65]. Huang et al. noted that $\mathrm{Pb}$ poisoning increased mRNA expression of ATF4, PERK, caspase-3, caspase-12, eIF2 $\alpha$, and CHOP in chicken testes [66]. This indicated that $\mathrm{Pb}$ induces apoptosis via $\mathrm{CHOP} /$ caspase-3 signal pathway and ER stress in chicken testes. The activation of a major ER stress transducer, the dissociated PERK, activates PERK which leads to the elF2 $\alpha$ phosphorylation and in sensitization of transcription factor ATF4. Upregulation of CHOP is caused by sustained ATF4 overexpression. Furthermore, CHOP is crucial mediator of ER stress-induced apoptosis. Under standard conditions, CHOP is expressed at low rates and under extended ER stress, $\mathrm{CHOP}$ is expressed at high levels and triggers apoptosis. After ER stress, caspase-12 dissociates and is activated and further activates caspase-3. Then, caspase-3 performs apoptosis.

Wang et al. showed that $\mathrm{Se}$ supplementation alleviates accumulation of $\mathrm{Pb}$ in testes of chicken [67]. Additionally, other studies demonstrated that Se alleviates Pb-induced oxidative stress. Likewise, Huang et al. illustrated that SOD, GPX, and GST activities were reduced by Se co-administration with $\mathrm{Pb}$ in chicken testes. Also, Se supplementation had protective effects on apoptosis. Jin et al. showed that triggered apoptosis and caspace- 3 raised by $\mathrm{Pb}$ poisoning on chicken kidneys was alleviated through $\mathrm{Se}$ supplementation [68]. Additionally, Wang et al. showed that $\mathrm{Pb}$ poisoning triggers mRNA expression increase of caspace-3, caspace-12, ATF4, and GRP78, and alleviation occurs via Se supplementation in chicken kidneys [69].

In the same way, $\mathrm{Pb}$-induced increase of $C H O P, e I F 2 \alpha$, and PERK mRNA expression and these effects were alleviated by Se in chicken testes [36]. These results indicate that Pb-induced apoptosis, oxidative stress, and ER stress are alleviated by Se via CHOP/caspase-3 signal pathway in the chicken testes [36]. Futhermore, $\mathrm{Li}$ et al. in a study on $\mathrm{Pb}-\mathrm{Se}$ interaction found that Se supplementation alleviated the activation of NF-kB pathway through the reduction of NF- $\kappa B, C O X-2$ and TNF- $\alpha$ expression in chicken neutrophils [70].

Lead, in addition, induces the mRNA expression of NF- $\kappa B$, TNF- $\alpha$, COX-2, PTGEs, iNOS, HSP27, HSP40, HSP60, HSP70, and HSP90, the NO content, and the iNOS activity in chicken liver. Also in this case, Se supplementation alleviated those changes [31]. Likewise, mRNA expression of $i N O S, N F-\kappa B$, $\mathrm{COX}-2$, and TNF- $\alpha$, NO content and $\mathrm{Pb}$ deposition was ameliorated via Se supplementation in the testes of chicken [67]. In the same way, the results of another study indicated that Se alleviated the changes caused by $\mathrm{Pb}$ exposure on $\mathrm{Bcl}-2 \mathrm{mRNA}$ and protein expression, the increased $\mathrm{NO}$ content, the iNOS activity, the relative mRNA and the protein expression of iNOS, the ER-related genes, and caspase-3 
and caspase-12 protein expression. Selenium attenuated those changes caused by $\mathrm{Pb}$ and $\mathrm{Pb}$-induced apoptosis via ER stress in chicken kidneys. In agreement with the above, Zhao et al. demonstrated that Se supplementation alleviated $\mathrm{Pb}$ induced apoptosis, PI3K/Akt pathway suppression and oxidative stress in chicken splenic lymphocytes [71].

In chicken neutrophils the mRNA expression levels of 23 selenoproteins (except of GPX3) and $\mathrm{TNF}-\alpha, \mathrm{NF}-\mathrm{kB}$, and iNOS were dramatically raised during $\mathrm{Pb}$ poisoning. However, Se supplementation alleviated this trend of inflammation factors, increased the mRNA levels of selenoproteins and decreased serum $\mathrm{Pb}$ content. Li et al. found positive correlations among inflammatory factors, besides COX-2. COX-2 might have played a principal function in Se antagonism against Pb [70]. Jiao et al. demonstrated that in chicken bursa of Fabricious, Se co-supplementation with $\mathrm{Pb}$ alleviated the inflammatory factors ( $I L-4, I L-6, I L-12 \beta$, and $I L-17)$ mRNA levels increase that were caused due to $\mathrm{Pb}$ poisoning [65]. In accordance with previous studies, Xing et al. demonstrated that $\mathrm{Pb}$ treatment increased significantly the expression of TGF- $\beta 4, I L-4, I L-8, I L-10, I L-12, I L-1 \beta, I L-1 R$ and reduced that of $I F N-\gamma$ and $I L-2$. Neutrophil injury and impair immune function in chicken could be induced by $\mathrm{Pb}$ poisoning [35]. There was a correlation between five HSPs and nine cytokines. IFN- $\gamma$ and IL-2 were negatively correlated with other parameters, but there was a positive correlation between TGF- $\beta 4, I L-12$, IL-10, IL-8, IL-4, IL-1R, IL-1 $\beta$, HSP90, HSP70, HSP60, HSP40, and HSP27. In contrast, HSP70, HSP60, and HSP40 were highly related to $I L-1 \beta$ [35]. Zhu et al. [72] showed that Pb triggered apoptosis in chicken embryonic neurocytes and brain tissues via mitochondrial pathway. In brain tissues of chicken, $\mathrm{Pb}$ induced a time-dependent effect on the decrease of selenoprotein M, GPX4, and in embryonic neurocytes $\mathrm{Pb}$ induced the mRNA decrease of selenoprotein U. Furthermore, multivariate correlation analysis demonstrated positive correlations between twenty-five selenoproteins; four apoptosis-related genes (caspase-3, Cyt-c, p53, and Bax); and between Bcl-2 and the selenoproteins in the embryonic neurocytes and chicks brain tissues [72].

In chicken hearts, mRNA expression levels of PTGEs, COX-2, TNF- $\alpha$, and NF- $\kappa B$ were decreased with implementation of Se supplementary diet compared with the $\mathrm{Pb}$ diet group. The results indicated that Se antagonized $\mathrm{Pb}$ induced inflammation [73]. Also, Se protects from $\mathrm{Pb}$ poisoning and alleviates the decrease of mRNA levels of SPS2, Sepx1, selenoprotein 15, selenoprotein M, Sepw1, TXNRD1, TXNRD3, TXNRD3, DIO1, DIO3, Sepn1, selenoprotein K, selenoprotein S, selenoprotein T, selenoprotein H, selenoprotein I, selenoprotein $\mathrm{U}$, selenoprotein $\mathrm{Pb}$, Sepp1, selenoprotein $\mathrm{O}, \mathrm{GPX} 2$, GPX3, and GPX4 [73]. Similarly, another study showed that during Pb toxicity the mRNA levels of $N F-\kappa B, T N F-\alpha, C O X-2$, and $i N O S$ in chickens' peripheral blood lymphocytes were significantly higher than in the control [63]. In correspondence with previous research outcomes, the results proposed that excess $\mathrm{Pb}$ could cause inflammation of chicken peripheral blood lymphocytes. However, Se supplementation decreased $\mathrm{Pb}$ toxicity-induced increase of $\operatorname{HSP}(27,40,60,70,90), C O X-2, T N F-\alpha$, iNOS, HO-1, and NF- $\kappa B$ [63]. Gao et al. [74], illustrated that dietary Se ameliorated Pb toxicity in the cartilage tissue of broiler chicken. More specifically, Se alleviated the downtrend of the expression of selenoprotein GPX4, GPX2, GPX1, DIO1, DIO2, TXNRD2, TXNRD3, Sepx1, selenoprotein O, selenoprotein K, selenoprotein M, selenoprotein T, selenoprotein W, Sepn1, selenoprotein 15, selenoprotein I, and selenoprotein U triggered by $\mathrm{Pb}$ exposure in the meniscus cartilage. Additionally, in the sword cartilage, Se alleviated the downtrend of mRNA expression of DIO2, DIO3, TXNRD1, TXNRD2, selenoprotein K, selenoprotein W, selenoprotein I, selenoprotein H, SPS2, Sepx1, selenoprotein 15, selenoprotein O, selenoprotein M, selenoprotein P, selenoprotein T, selenoprotein n1, GPX2, GPX3, and GPX4 induced by Pb toxicity [74].

Finally, 25 selenoprotein genes (TXNRD1, TXNRD2, and TXNRD3, selenoprotein $\mathrm{H}$, selenoprotein $\mathrm{I}$, selenoprotein $\mathrm{K}$, selenoprotein $\mathrm{T}$, selenoprotein $\mathrm{M}$, selenoprotein $\mathrm{W}$, selenoprotein $\mathrm{Pb}$, selenoprotein $\mathrm{S}$, selenoprotein O, selenoprotein U, DIO1, DIO2, DIO3, selenoprotein 15, Sepn1, Sepp1, Sepx1, SPS2, GPX1, GPX2, GPX3, and GPX4) in chicken testes showed highest expression levels in the Se supplemented groups than in the $\mathrm{Pb}$ exposed chicken groups indicating an increase of the antioxidative potential due to Se supplementation. Also, there were positive correlations between the selenoproteins gene expression and the expression of five HSPs (HSP40, HSP27, HSP90, HSP60 and HSP70) [36]. 
From the aforementioned, it can be concluded that Se supplementation can alleviate the toxic effects of $\mathrm{Pb}$, by increasing the antioxidative potential in several chicken tissues via upregulation of many antioxidant proteins. A summary of selected studies in chicken describing the effects of heavy metals on various factors, HSP, and selenoproteins is shown in Table 1. 
Table 1. A summary of selected studies in chicken describing effects of heavy metals on various factors, heat shock proteins (HSP), and selenoproteins.

\begin{tabular}{|c|c|c|c|c|c|c|c|c|c|}
\hline $\begin{array}{l}\text { Type of } \\
\text { Supplementation }\end{array}$ & Heavy Metal & Tissue & $\begin{array}{l}\text { Inflammation } \\
\text { Factors and Other } \\
\text { Proteins }\end{array}$ & $\begin{array}{l}\text { Heat Stress } \\
\text { Proteins }\end{array}$ & $\begin{array}{l}\text { Cell Death } \\
\text { Regulation } \\
\text { Proteins }\end{array}$ & Selenoproteins & Other Results & $\begin{array}{l}\text { Analytical } \\
\text { Method }\end{array}$ & Reference \\
\hline $\begin{array}{l}\mathrm{Na}_{2} \mathrm{SeO}_{3} \\
2 \mathrm{mg} / \mathrm{Kg}\end{array}$ & $\begin{array}{l}\mathrm{CdCl}_{2} \\
150 \mathrm{mg} / \mathrm{Kg}\end{array}$ & $\begin{array}{l}\text { Liver } \\
\text { (in vivo) }\end{array}$ & $\begin{array}{l}\text { Se/Cd alleviation of } \\
\text { increased mRNA } \\
\text { levels of NF-kB, } \\
\text { COX-2, PTGES, } \\
\text { TNF- } \alpha \text {, and IL-1 in } \\
\text { relation to Cd } \\
\text { treatment }\end{array}$ & $\begin{array}{l}\text { Alleviation of } \\
\text { increased } \\
\text { mRNA/protein } \\
\text { levels of HSP60, } \\
\text { HSP70, HSP90 in } \\
\text { relation to Cd } \\
\text { treatment }\end{array}$ & No & No & $\begin{array}{l}\text { Decrease of } \mathrm{Cd} \\
\text { induction (decrease } \\
\text { of } \mathrm{Li}, \mathrm{B}, \mathrm{Ca}, \mathrm{Fe}, \mathrm{Ti} \text {, } \\
\mathrm{Cu}, \mathrm{Mo}, \mathrm{Cd}, \mathrm{Cr}, \mathrm{Se} \text {, } \\
\mathrm{Sr}, \mathrm{Ba} \text {, and } \mathrm{Hg} \\
\text { concentrations) }\end{array}$ & $\begin{array}{l}\text { RT-PCR, } \\
\text { Western blot }\end{array}$ & [47] \\
\hline $\begin{array}{l}\mathrm{Na}_{2} \mathrm{O}_{3} \mathrm{Se} \\
1 \mathrm{mg} / \mathrm{Kg}\end{array}$ & $\begin{array}{l}\mathrm{Pb}(\mathrm{CH} 3 \mathrm{COO})_{2} \\
350 \mathrm{mg} / \mathrm{Kg}\end{array}$ & $\begin{array}{l}\text { Neutrophils } \\
\text { (in vivo) }\end{array}$ & $\begin{array}{l}\text { Decrease of (IL-1 } \beta \text {, } \\
\text { IL-1R, IL-4, IL-8, } \\
\text { IL-10, IL-12, } \\
\text { TGF- } \beta 4 \text { ) increased } \\
\text { the mRNA } \\
\text { expression of IL-2 } \\
\text { and IFN- } \gamma\end{array}$ & $\begin{array}{l}\text { Decrease of protein } \\
\text { HSP27, }-40,-60,-70, \\
-90 \text { and mRNA of } \\
\text { HSP } 60 \text { and }-70 \text { in } \\
\text { relation to } \mathrm{Pb} \\
\text { treatment }\end{array}$ & No & No & No & $\begin{array}{l}\text { RT-PCR, } \\
\text { Western blot }\end{array}$ & {$[35]$} \\
\hline $\begin{array}{l}\mathrm{Na}_{2} \mathrm{SeO}_{3} \\
2 \mathrm{mg} / \mathrm{Kg}\end{array}$ & $\begin{array}{l}\mathrm{CdCl}_{2} \\
150 \mathrm{mg} / \mathrm{Kg}\end{array}$ & $\begin{array}{l}\text { Pancreas } \\
\text { (in vivo) }\end{array}$ & No & No & No & No & $\begin{array}{l}\mathrm{Se} / \mathrm{Cd} \text { treatment } \\
\text { alleviated the } \\
\text { mRNA increase of } \\
\text { T-SOD, CAT, } \\
\text { GSH-Px, T-AOC } \\
\text { caused by Cd } \\
\text { toxicity in relation } \\
\text { to control }\end{array}$ & $\begin{array}{l}\text { ICP-MS, } \\
\text { RT-PCR }\end{array}$ & [18] \\
\hline $\begin{array}{l}\mathrm{Na}_{2} \mathrm{SeO}_{3} \\
1 \mathrm{mg} / \mathrm{Kg} \mathrm{Se}\end{array}$ & $\begin{array}{l}\mathrm{Pb}\left(\mathrm{CH}_{3} \mathrm{COO}\right)_{2} \\
350 \mathrm{mg} / \mathrm{L}\end{array}$ & $\begin{array}{l}\text { Testes } \\
\text { (in vivo) }\end{array}$ & No & No & $\begin{array}{l}\mathrm{Se} / \mathrm{Pb} \text { : } \\
\text { downregulation } \\
\text { of caspase-3, } \\
\text { caspase- } 12 \mathrm{in} \\
\text { relation to } \mathrm{Pb} \\
\text { treatment }\end{array}$ & $\begin{array}{l}\text { GPX upregulation } \\
\text { in Se treatment } \\
\text { and alleviation of } \\
\text { GPX } \\
\text { downregulation } \\
\text { induced by } \mathrm{Pb} \text { in } \\
\mathrm{Se} / \mathrm{Pb} \text { treatment }\end{array}$ & No & RT-PCR & {$[66]$} \\
\hline $\begin{array}{l}\mathrm{Na}_{2} \mathrm{SeO}_{3} \\
2 \mathrm{mg} / \mathrm{Kg}\end{array}$ & $\begin{array}{l}\mathrm{CdCl}_{2} \\
218.44 \mathrm{mg} / \mathrm{Kg}\end{array}$ & $\begin{array}{l}\text { Ovary } \\
\text { (in vivo) }\end{array}$ & $\begin{array}{l}\text { Se/Cd treatment } \\
\text { alleviated the } \\
\text { mRNA increase of } \\
\text { HK2, PK, SDH, } \\
\text { PbHX, LC3, Atg5, } \\
\text { Beclin 1, Dynein, } \\
\text { Lc3-I, Lc3-1l, mTOR } \\
\text { caused by Cd } \\
\text { toxicity in relation } \\
\text { to control }\end{array}$ & No & No & No & No & $\begin{array}{l}\text { q-PCR, } \\
\text { Western Blot }\end{array}$ & [49] \\
\hline
\end{tabular}


Table 1. Cont

\begin{tabular}{|c|c|c|c|c|c|c|c|c|c|}
\hline $\begin{array}{l}\text { Type of } \\
\text { Supplementation }\end{array}$ & Heavy Metal & Tissue & $\begin{array}{l}\text { Inflammation } \\
\text { Factors and Other } \\
\text { Proteins }\end{array}$ & $\begin{array}{l}\text { Heat Stress } \\
\text { Proteins }\end{array}$ & $\begin{array}{l}\text { Cell Death } \\
\text { Regulation } \\
\text { Proteins }\end{array}$ & Selenoproteins & Other Results & $\begin{array}{l}\text { Analytical } \\
\text { Method }\end{array}$ & Reference \\
\hline $\mathrm{Na}_{2} \mathrm{SeO}_{3} 1 \mathrm{mg} / \mathrm{Kg}$ & $\begin{array}{l}\mathrm{Pb}\left(\mathrm{CH}_{3} \mathrm{COO}\right)_{2} \\
350 \mathrm{mg} / \mathrm{L}\end{array}$ & $\begin{array}{l}\text { Kidney } \\
\text { (in vivo) }\end{array}$ & No & No & $\begin{array}{l}\text { caspase-3, } \\
\text { caspase-12, } \\
\mathrm{Bcl}-2 \text { increase } \\
\text { in Pb group } \\
\text { and } \\
\text { alleviation of } \\
\text { increase in } \\
\mathrm{Pb} / \text { Se group }\end{array}$ & No & No & $\begin{array}{l}\text { RT-PCR, } \\
\text { Western Blot }\end{array}$ & [69] \\
\hline $\begin{array}{l}\mathrm{Na}_{2} \mathrm{SeO}_{3} \\
2 \mathrm{mg} / \mathrm{Kg}\end{array}$ & $\begin{array}{l}\mathrm{CdCl}_{2} \\
150 \mathrm{mg} / \mathrm{Kg}\end{array}$ & $\begin{array}{l}\text { Kidney } \\
\text { (in vivo) }\end{array}$ & $\begin{array}{l}\text { Cd group: increase } \\
\text { in mRNA levels of } \\
\text { COX-2, NF-kB, } \\
\text { PTGES, and TNF- } \alpha \\
\text { Se/Cd group: } \\
\text { alleviation of } \\
\text { mRNA level } \\
\text { increase of NF-kB } \\
\text { and TNF- } \alpha \text {. } \\
\text { COX- } 2 \text { and PTGES } \\
\text { were not influenced }\end{array}$ & No & No & $\begin{array}{l}\text { (Decrease in the } \\
\text { mRNA levels of } \\
\text { GPX2, GPX3, } \\
\text { DIO3, } \\
\text { selenoprotein K, } \\
\text {-N, -O, -Pb, -S, -T, } \\
\text {-U, and -W } \\
\text { between the Cd } \\
\text { group and control, } \\
\text { not in the mRNA } \\
\text { levels of the GPX1, } \\
\text { GPX4, DIO1, } \\
\text { DIO2, Txnard1, -2, } \\
-3 \text {, selenoprotein } \\
\text { H, -I, -M, Sep15, } \\
\text { Sepp1, Sepx1, } \\
\text { SPS2) AND } \\
\text { (between Cd/Se } \\
\text { group and control } \\
\text { GPX2, GPX3, } \\
\text { selenoprotein T, } \\
\text {-U, and -W } \\
\text { smaller decrease) }\end{array}$ & No & RT-PCR & {$[28]$} \\
\hline
\end{tabular}


Table 1. Cont

\begin{tabular}{|c|c|c|c|c|c|c|c|c|c|}
\hline $\begin{array}{l}\text { Type of } \\
\text { Supplementation }\end{array}$ & Heavy Metal & Tissue & $\begin{array}{l}\text { Inflammation } \\
\text { Factors and Other } \\
\text { Proteins }\end{array}$ & $\begin{array}{l}\text { Heat Stress } \\
\text { Proteins }\end{array}$ & $\begin{array}{l}\text { Cell Death } \\
\text { Regulation } \\
\text { Proteins }\end{array}$ & Selenoproteins & Other Results & $\begin{array}{l}\text { Analytical } \\
\text { Method }\end{array}$ & Reference \\
\hline $\begin{array}{l}\mathrm{Na}_{2} \mathrm{SeO}_{3} \\
0.02 \mathrm{mg} / \mathrm{L}\end{array}$ & $\begin{array}{l}\mathrm{Pb}\left(\mathrm{CH}_{3} \mathrm{COO}\right)_{2} \\
12 \mathrm{mg} / \mathrm{L}\end{array}$ & $\begin{array}{l}\text { Spleen } \\
\text { (in vitro) }\end{array}$ & No & No & $\begin{array}{l}\text { Se/Pb: } \\
\text { increase due } \\
\text { to Pb } \\
\text { exposure of } \\
\text { p53, Bak, } \\
\text { caspace-3, } \\
\text { caspase-9, } \\
\text { Cyt-c and } \\
\text { decrease of } \\
\text { PL3K, Akt, } \\
\text { Bc12 alleviated } \\
\text { via Se } \\
\text { supplementation }\end{array}$ & No & $\begin{array}{l}\text { Se alleviated the } \\
\text { increase of MDA } \\
\text { levels due to Pb and } \\
\text { alleviated the } \\
\text { decrease in } \\
\text { antioxidant enzyme } \\
\text { activity (GPX, SOD, } \\
\text { and CAT) due to Pb } \\
\text { Additionally, ROS } \\
\text { levels in the control } \\
\text { group and the Se } \\
\text { group were not } \\
\text { significantly } \\
\text { different. Se } \\
\text { alleviated the } \\
\text { increase of ROS } \\
\text { levels due to } \mathrm{Pb}\end{array}$ & $\begin{array}{l}\text { RT-PCR, } \\
\text { Flow } \\
\text { cytometry, } \\
\text { Western Blot }\end{array}$ & [71] \\
\hline $\begin{array}{l}\mathrm{Na}_{2} \mathrm{SeO}_{3} \\
2 \mathrm{mg} / \mathrm{Kg}\end{array}$ & $\begin{array}{l}\mathrm{CdCl}_{2} \\
150 \mathrm{mg} / \mathrm{Kg}\end{array}$ & $\begin{array}{l}\text { Spleen } \\
\text { (in vivo) }\end{array}$ & No & No & $\begin{array}{l}\text { Se/Cd: } \\
\text { caspase-3, } \\
\text { caspase-9 } \\
\text { small } \\
\text { alleviation of } \\
\text { mRNA } \\
\text { increase due } \\
\text { to Cd } \\
\text { treatment but } \\
\text { extensive } \\
\text { alleviation of } \\
\text { increase of } \\
\text { caspase-3 } \\
\text { protein levels }\end{array}$ & $\begin{array}{l}\mathrm{Se} / \mathrm{Cd} \text { treatment } \\
\text { alleviate the } \\
\text { decrease of TrxR1, } \\
\text { GPX1 due to Cd } \\
\text { treatment }\end{array}$ & $\begin{array}{l}\mathrm{Cd} \text { increased } \mathrm{H}_{2} \mathrm{O}_{2} \\
\text { and MDA and SOD } \\
\text { but T-AOC, CAT } \\
\text { decreased Bax, } \\
\text { Cyt-c, Bak } \\
\text { alleviation of } \\
\text { increase due to Cd }\end{array}$ & $\begin{array}{l}\text { ICP-MS, } \\
\text { Western Blot, } \\
\text { RT-PCR }\end{array}$ & {$[54]$} \\
\hline $\begin{array}{l}\mathrm{Na}_{2} \mathrm{SeO}_{3} \\
2 \mathrm{mg} / \mathrm{Kg}\end{array}$ & $\begin{array}{l}\mathrm{CdCl}_{2} \\
150 \mathrm{mg} / \mathrm{Kg}\end{array}$ & $\begin{array}{l}\text { Liver } \\
\text { (in vivo) }\end{array}$ & $\begin{array}{l}\text { Se/Cd: iNOS } \\
\text { alleviaton of } \\
\text { increase of mRNA } \\
\text { levels due to Cd } \\
\text { similarly in protein } \\
\text { levels }\end{array}$ & No & $\begin{array}{l}\text { Se/Cd: } \\
\text { caspase-3, } \\
\text { caspase-9, p53 } \\
\text { alleviation of } \\
\text { increase of } \\
\text { mRNA levels } \\
\text { due to Cd } \\
\text { protein levels }\end{array}$ & No & $\begin{array}{l}\text { Se/Cd: Cyt-c } \\
\text { alleviation of } \\
\text { increase due to } \mathrm{Cd}\end{array}$ & $\begin{array}{l}\text { RT-PCR, } \\
\text { Western Blot, } \\
\text { TUNEL assay }\end{array}$ & [45] \\
\hline
\end{tabular}


Table 1. Cont

\begin{tabular}{|c|c|c|c|c|c|c|c|c|c|}
\hline $\begin{array}{l}\text { Type of } \\
\text { Supplementation }\end{array}$ & Heavy Metal & Tissue & $\begin{array}{l}\text { Inflammation } \\
\text { Factors and Other } \\
\text { Proteins }\end{array}$ & $\begin{array}{l}\text { Heat Stress } \\
\text { Proteins }\end{array}$ & $\begin{array}{l}\text { Cell Death } \\
\text { Regulation } \\
\text { Proteins }\end{array}$ & Selenoproteins & Other Results & $\begin{array}{l}\text { Analytical } \\
\text { Method }\end{array}$ & Reference \\
\hline $\begin{array}{l}\mathrm{Na}_{2} \mathrm{SeO}_{3} \\
2 \mathrm{mg} / \mathrm{Kg}\end{array}$ & $\begin{array}{l}\mathrm{CdCl}_{2} \\
150 \mathrm{mg} / \mathrm{Kg}\end{array}$ & $\begin{array}{l}\text { Neutrophils } \\
\text { (in vivo) }\end{array}$ & $\begin{array}{l}\text { Se/Cd: alleviated } \\
\text { increase of mRNA } \\
\text { levels of COX-2 and } \\
\text { the decrease of } \\
\text { TNF- } \alpha \text { due to Cd }\end{array}$ & $\begin{array}{l}\text { Se/Cd: HSP } 40, \text { HSP } \\
70, \text { HSP } 90 \\
\text { alleviation of } \\
\text { increase of mRNA } \\
\text { levels due to Cd but } \\
\text { in HSP } 60 \text { is the } \\
\text { same with Cd } \\
\text { group }\end{array}$ & $\begin{array}{l}\text { Se/Cd: NF-kB, } \\
\text { IL-2, IL-4, } \\
\text { IL-17, IFN- } \gamma \\
\text { alleviation of } \\
\text { mRNA levels } \\
\text { increase due } \\
\text { to Cd and } \\
\text { IL-10, IL-1 } \beta \text {, } \\
\text { iNOS } \\
\text { alleviation of } \\
\text { decrease of } \\
\text { mRNA levels } \\
\text { due to Cd }\end{array}$ & No & No & RT-PCR & [41] \\
\hline $\mathrm{Na}_{2} \mathrm{SeO}_{3} 1 \mathrm{mg} / \mathrm{Kg}$ & $\begin{array}{l}\mathrm{Pb}\left(\mathrm{CH}_{3} \mathrm{COO}\right)_{2} \\
350 \mathrm{mg} / \mathrm{Kg}\end{array}$ & $\begin{array}{l}\text { Testes } \\
\text { (in vivo) }\end{array}$ & No & $\begin{array}{l}\text { Se/Pb: alleviation of } \\
\text { increase of HSP27, } \\
-40,-60,-70,-90 \\
\text { mRNA levels } \\
\text { caused by Pb } \\
\text { toxicity in relation } \\
\text { to control }\end{array}$ & No & $\begin{array}{l}\text { DIO1, DIO2, } \\
\text { DIO3, GPX1, } \\
\text { GPX2, GPX3, } \\
\text { GPX4, } \\
\text { selenoprotein H, } \\
-\mathrm{I},-\mathrm{K},-\mathrm{M},-\mathrm{O},-\mathrm{Pb}, \\
-\mathrm{S},-\mathrm{T},-\mathrm{U},-\mathrm{W},-15, \\
\text { Sepn1, Sepp1, } \\
\text { Sepx1, SPS2, } \\
\text { Txnrd1, -2 and -3 } \\
\text { increase of mRNA } \\
\text { expression in Se } \\
\text { group and } \\
\text { alleviation of } \\
\text { increase in Se/Cd } \\
\text { group }\end{array}$ & No & qRT-PCR & [36] \\
\hline
\end{tabular}


Table 1. Cont

\begin{tabular}{|c|c|c|c|c|c|c|c|c|c|}
\hline $\begin{array}{l}\text { Type of } \\
\text { Supplementation }\end{array}$ & Heavy Metal & Tissue & $\begin{array}{l}\text { Inflammation } \\
\text { Factors and Other } \\
\text { Proteins }\end{array}$ & $\begin{array}{l}\text { Heat Stress } \\
\text { Proteins }\end{array}$ & $\begin{array}{l}\text { Cell Death } \\
\text { Regulation } \\
\text { Proteins }\end{array}$ & Selenoproteins & Other Results & $\begin{array}{l}\text { Analytical } \\
\text { Method }\end{array}$ & Reference \\
\hline $\begin{array}{l}\mathrm{Na}_{2} \mathrm{SeO}_{3} \\
1 \mathrm{mg} / \mathrm{L}\end{array}$ & $\begin{array}{l}\mathrm{Pb}\left(\mathrm{CH}_{3} \mathrm{COO}\right)_{2} \\
350 \mathrm{mg} / \mathrm{L}\end{array}$ & $\begin{array}{l}\text { Neutrophils } \\
\text { (in vivo) }\end{array}$ & $\begin{array}{l}\text { Se treatment } \\
\text { slightly increased } \\
\text { TNF- } \alpha 3 \text {, Cox-2, } \\
\text { iNOS, NF- } \mathrm{k} B \\
\text { mRNA levels in } \\
\text { relation to control } \\
\text { while Pb increased } \\
\text { TNF- } \alpha 3, \text { Cox-2, } \\
\text { iNOS, NF- } \mathrm{k} B \\
\text { mRNA levels in } \\
\text { relation to control } \\
\text { and Se/Pb treatment } \\
\text { alleviated } \\
\text { aforementioned } \\
\text { increase of mRNA } \\
\text { levels }\end{array}$ & No & $\begin{array}{l}\text { GPX2, GPX3, } \\
\text { GPX4, DIO1, } \\
\text { DIO2, DIO3, } \\
\text { Txnrd1, } \\
\text { Txnrd2, } \\
\text { Txnrd3, SPS2, } \\
\text { Sepx1, Sepp1, } \\
\text { selenoprotein } \\
\mathrm{S},-\mathrm{K},-\mathrm{O},-\mathrm{U}, \\
-\mathrm{H},-15, \\
\text { and }-\mathrm{M}, \\
\text { significantly } \\
\text { higher in Se } \\
\text { group than in } \\
\text { control and } \\
\text { slightly higher } \\
\text { in Pb } \\
\text { treatment in } \\
\text { relation to } \\
\text { control. Se/Pb } \\
\text { treatment } \\
\text { intensified the } \\
\text { increase in } \mathrm{Pb} \\
\text { treatment in } \\
\text { relation to } \\
\text { control }\end{array}$ & No & No & $\begin{array}{l}\text { RT-PCR, } \\
\text { Western Blot }\end{array}$ & [70] \\
\hline $\begin{array}{l}\mathrm{Na}_{2} \mathrm{SeO}_{3} \\
0.02 \mathrm{mg} / \mathrm{L}\end{array}$ & $\begin{array}{l}\mathrm{CdCl}_{2} \\
0.2 \mathrm{mg} / \mathrm{L}\end{array}$ & $\begin{array}{l}\text { Neutrophils } \\
\text { (in vitro) }\end{array}$ & $\begin{array}{l}\text { Se/Cd treatment } \\
\text { alleviated the } \\
\text { increase of mRNA } \\
\text { levels of IL-1 } \beta, I L-4, \\
\text { IL-10, IFN- } \gamma, \text { NF-KB, } \\
\text { iNOS, COX-2, } \\
\text { TNF- } \alpha, \text { and PGE2 } \\
\text { due to Cd present } \\
\text { and also alleviated } \\
\text { the mRNA levels } \\
\text { decrease of IL-17 } \\
\text { due to Cd toxicity } \\
\text { in relation to control }\end{array}$ & No & No & No & No & $\begin{array}{l}\text { TUNEL assay, } \\
\text { RT-PCR, } \\
\text { Western blot }\end{array}$ & [46] \\
\hline
\end{tabular}


Table 1. Cont

\begin{tabular}{|c|c|c|c|c|c|c|c|c|c|}
\hline $\begin{array}{l}\text { Type of } \\
\text { Supplementation }\end{array}$ & Heavy Metal & Tissue & $\begin{array}{l}\text { Inflammation } \\
\text { Factors and Other } \\
\text { Proteins }\end{array}$ & $\begin{array}{l}\text { Heat Stress } \\
\text { Proteins }\end{array}$ & $\begin{array}{l}\text { Cell Death } \\
\text { Regulation } \\
\text { Proteins }\end{array}$ & Selenoproteins & Other Results & $\begin{array}{l}\text { Analytical } \\
\text { Method }\end{array}$ & Reference \\
\hline $\begin{array}{l}\mathrm{Na}_{2} \mathrm{SeO}_{3} \\
1 \mathrm{mg} / \mathrm{L}\end{array}$ & $\begin{array}{l}\mathrm{Pb}\left(\mathrm{CH}_{3} \mathrm{COO}\right)_{2} \\
350 \mathrm{mg} / \mathrm{L}\end{array}$ & $\begin{array}{l}\text { Testes } \\
\text { (in vivo) }\end{array}$ & $\begin{array}{l}\mathrm{Se} / \mathrm{Pb} \text { treatment } \\
\text { alleviated the } \\
\text { increase of NF-kB, } \\
\text { TNF- } \alpha, \text { COX-2, } \\
\text { PTGE mRNA, } \\
\text { and NF- } \mathrm{kB} \text { protein } \\
\text { levels due to Pb } \\
\text { toxicity in relation } \\
\text { to control }\end{array}$ & $\begin{array}{l}\mathrm{Se} / \mathrm{Pb} \text { treatment } \\
\text { alleviated the } \\
\text { mRNA levels } \\
\text { increase of } \mathrm{HSP} 60 \text {, } \\
-70,-90 \text { due to } \mathrm{Pb} \\
\text { toxicity in relation } \\
\text { to control }\end{array}$ & No & No & $\begin{array}{l}\mathrm{Se} / \mathrm{Pb} \text { treatment } \\
\text { alleviated the } 90 \\
\text { days } \mathrm{Pb} \\
\text { accumulation in } \\
\text { testes }\end{array}$ & $\begin{array}{l}\text { qRT-PCR, } \\
\text { Western Blot }\end{array}$ & [67] \\
\hline $\begin{array}{l}\mathrm{Na}_{2} \mathrm{SeO}_{3} \\
1 \mathrm{mg} / \mathrm{L}\end{array}$ & $\begin{array}{l}\mathrm{Pb}\left(\mathrm{CH}_{3} \mathrm{COO}\right)_{2} \\
350 \mathrm{mg} / \mathrm{L}\end{array}$ & $\begin{array}{l}\text { Bursa of } \\
\text { Fabricius } \\
\text { (in vivo) }\end{array}$ & $\begin{array}{l}\text { Se/Pb alleviated the } \\
\text { mRNA increase of } \\
\text { IL-2, IL-4, IL-6, } \\
\text { IL-12 } \beta \text {, IL-17, } \\
\text { and the mRNA } \\
\text { decrease of IFN- } \gamma \\
\text { caused by Pb } \\
\text { toxicity in relation } \\
\text { to control }\end{array}$ & No & No & No & $\begin{array}{l}\text { T-AOC, GPX, GST, } \\
\text { SOD, and CAT } \\
\text { activities increase in } \\
\text { Se treatment in } \\
\text { relation to control, } \\
\text { in Pb treatment } \\
\text { T-AOC, GPX, GST, } \\
\text { SOD, and CAT } \\
\text { activities decreased } \\
\text { in relation to } \\
\text { control and Se/Pb } \\
\text { treatment alleviated } \\
\text { this decrease }\end{array}$ & qRT-PCR & [65] \\
\hline $\begin{array}{l}\mathrm{Na}_{2} \mathrm{SeO}_{3} \\
1 \mathrm{mg} / \mathrm{L}\end{array}$ & $\begin{array}{l}\mathrm{Pb}\left(\mathrm{CH}_{3} \mathrm{COO}\right)_{2} \\
350 \mathrm{mg} / \mathrm{L}\end{array}$ & $\begin{array}{l}\text { Nervous } \\
\text { Tissues } \\
\text { (in vivo) }\end{array}$ & No & No & $\begin{array}{l}\mathrm{Se} / \mathrm{Pb} \\
\text { treatment } \\
\text { alleviate the } \\
\text { decrease of } \\
\text { Bcl2 protein/ } \\
\text { mRNA levels } \\
\text { while alleviate } \\
\text { the increase of } \\
\text { protein/mRNA } \\
\text { levels in p53, } \\
\text { Bax, Cyt-c, } \\
\text { caspases-3 } \\
\text { due to Pb } \\
\text { toxicity }\end{array}$ & No & No & qRT-PCR & [72] \\
\hline
\end{tabular}


Table 1. Cont

\begin{tabular}{|c|c|c|c|c|c|c|c|c|c|}
\hline $\begin{array}{l}\text { Type of } \\
\text { Supplementation }\end{array}$ & Heavy Metal & Tissue & $\begin{array}{l}\text { Inflammation } \\
\text { Factors and Other } \\
\text { Proteins }\end{array}$ & $\begin{array}{l}\text { Heat Stress } \\
\text { Proteins }\end{array}$ & $\begin{array}{l}\text { Cell Death } \\
\text { Regulation } \\
\text { Proteins }\end{array}$ & Selenoproteins & Other Results & $\begin{array}{l}\text { Analytical } \\
\text { Method }\end{array}$ & Reference \\
\hline $\begin{array}{l}\mathrm{Na}_{2} \mathrm{SeO}_{3} \\
1 \mathrm{mg} / \mathrm{L}\end{array}$ & $\begin{array}{l}\mathrm{Pb}\left(\mathrm{CH}_{3} \mathrm{COO}\right)_{2} \\
350 \mathrm{mg} / \mathrm{L}\end{array}$ & $\begin{array}{l}\text { Heart } \\
\text { (in vivo) }\end{array}$ & $\begin{array}{l}\mathrm{Se} / \mathrm{Pb} \text { treatment } \\
\text { alleviated the } \\
\text { increase of NF-kB, } \\
\text { TNF-a, COX-2 and } \\
\text { PTGEs mRNA } \\
\text { levels due to Pb } \\
\text { toxicity }\end{array}$ & No & No & $\begin{array}{l}\text { Se/Pb treatment } \\
\text { alleviated the } \\
\text { decrease of } \\
\text { mRNA levels of } \\
\text { GPX1, -2,--3, } \\
\text { and }-4 \text {, Txnrd1, -2, } \\
\text {-3, DIO1,-2,-3, } \\
\text { selenoprotein N1, } \\
-\mathrm{K},-\mathrm{S},-\mathrm{T},-\mathrm{O},-\mathrm{H} \text {, } \\
-\mathrm{M},-15,-\mathrm{U},-\mathrm{Pb} \text {, } \\
\mathrm{Sepp} 1 \text {, Sepn1, } \\
\text { Sepw1, Sepx1, } \\
\text { SPS2 due to Pb } \\
\text { toxicity in relation } \\
\text { to control }\end{array}$ & No & qRT-PCR & [73] \\
\hline $\begin{array}{l}\mathrm{Na}_{2} \mathrm{SeO}_{3} \\
2 \mathrm{mg} / \mathrm{Kg}\end{array}$ & $\begin{array}{l}\mathrm{CdCl}_{2} \\
150 \mathrm{mg} / \mathrm{Kg}\end{array}$ & $\begin{array}{l}\text { Heart } \\
\text { (in vivo) }\end{array}$ & No & No & $\begin{array}{l}\text { Se/Cd } \\
\text { treatment } \\
\text { alleviated the } \\
\text { increase of } \\
\text { JNK, AMPK } \\
\text { and PPAR } \alpha \\
\text { due to Cd } \\
\text { exposure and } \\
\text { alleviated the } \\
\text { decrease of } \\
\text { P-JNK }\end{array}$ & No & No & $\begin{array}{l}\text { qRT-PCR, } \\
\text { Western Blot }\end{array}$ & [75] \\
\hline $\begin{array}{l}\mathrm{Na}_{2} \mathrm{SeO}_{3} \\
1 \mathrm{mg} / \mathrm{L}\end{array}$ & $\begin{array}{l}\mathrm{Pb}\left(\mathrm{CH}_{3} \mathrm{COO}\right)_{2} \\
350 \mathrm{mg} / \mathrm{L}\end{array}$ & $\begin{array}{l}\text { Kidney } \\
\text { (in vivo) }\end{array}$ & No & No & $\begin{array}{l}\mathrm{Se} / \mathrm{Pb} \\
\text { treatment } \\
\text { alleviated the } \\
\text { decrease of } \\
\text { mRNA levels } \\
\text { of mfn1, drp1, } \\
\text { opa1, mff, } \\
\text { mfn2 due to } \\
\mathrm{Pb} \text { toxicity }\end{array}$ & No & $\begin{array}{l}\mathrm{Se} / \mathrm{Pb} \text { treatment } \\
\text { alleviated the } \\
\text { decrease of } \mathrm{Cpx} \text {, } \\
\mathrm{SOD}, \mathrm{MDA}, \mathrm{ATPase} \\
\text { activities, } \\
\text { Mitochondrial } \\
\text { complex } \mathrm{V},-\mathrm{II},-\mathrm{I} \\
\text { activities due to } \mathrm{Pb} \\
\text { toxicity }\end{array}$ & $\begin{array}{l}\text { RT-PCR, } \\
\text { Western Blot, } \\
\text { TUNEL assay }\end{array}$ & {$[68]$} \\
\hline
\end{tabular}


Table 1. Cont

\begin{tabular}{|c|c|c|c|c|c|c|c|c|c|}
\hline $\begin{array}{l}\text { Type of } \\
\text { Supplementation }\end{array}$ & Heavy Metal & Tissue & $\begin{array}{l}\text { Inflammation } \\
\text { Factors and Other } \\
\text { Proteins }\end{array}$ & $\begin{array}{l}\text { Heat Stress } \\
\text { Proteins }\end{array}$ & $\begin{array}{l}\text { Cell Death } \\
\text { Regulation } \\
\text { Proteins }\end{array}$ & Selenoproteins & Other Results & $\begin{array}{l}\text { Analytical } \\
\text { Method }\end{array}$ & Reference \\
\hline $\begin{array}{l}\mathrm{Na}_{2} \mathrm{SeO}_{3} \\
1 \mathrm{mg} / \mathrm{L}\end{array}$ & $\begin{array}{l}\mathrm{Pb}\left(\mathrm{CH}_{3} \mathrm{COO}\right)_{2} \\
350 \mathrm{mg} / \mathrm{L}\end{array}$ & $\begin{array}{l}\text { Lymphocytes } \\
\text { (in vivo) }\end{array}$ & $\begin{array}{l}\mathrm{Se} / \mathrm{Pb} \text { treatment } \\
\text { alleviated the } \\
\text { mRNA increase of } \\
\text { iNOS, TNF-a, } \\
\mathrm{COX}-2, \mathrm{NF}-\mathrm{KB} \text { due } \\
\text { to } \mathrm{Pb} \text { in relation to } \\
\text { control }\end{array}$ & $\begin{array}{l}\mathrm{Se} / \mathrm{Pb} \text { treatment } \\
\text { alleviated the } \\
\text { increase of mRNA } \\
\text { levels of HSP27, }-40 \text {, } \\
-60,-70,-90 \text { due to } \\
\mathrm{Pb} \text { toxicity in } \\
\text { relation to control }\end{array}$ & No & No & No & RT-PCR & {$[63]$} \\
\hline $\begin{array}{l}\mathrm{Na}_{2} \mathrm{SeO}_{3} \\
1 \mathrm{mg} / \mathrm{L}\end{array}$ & $\begin{array}{l}\mathrm{Pb}\left(\mathrm{CH}_{3} \mathrm{COO}\right)_{2} \\
350 \mathrm{mg} / \mathrm{L}\end{array}$ & $\begin{array}{l}\text { Cartilage } \\
\text { (in vivo) }\end{array}$ & No & No & No & $\begin{array}{l}\text { Se alleviated the } \\
\text { downtrend of the } \\
\text { expression of } \\
\text { GPX1, -2, -4, } \\
\text { Txnrd2, Txnrd3, } \\
\text { DIO1, DIO2, } \\
\text { selenoprotein I, } \\
\text {-U, Sepx1, } \\
\text { selenoprotein K, } \\
\text {-W, -O, -M, Sep15, } \\
\text { Sepnn1, } \\
\text { selenoprotein S, } \\
\text { and -T induced by } \\
\text { Pb in relation to } \\
\text { control }\end{array}$ & $\begin{array}{l}\mathrm{Se} / \mathrm{Pb} \text { treatment } \\
\text { alleviated the } \\
\text { concentration of } \mathrm{Pb} \\
\text { in sword cartilage } \\
\text { tissue }\end{array}$ & $\begin{array}{l}\text { qRT-PCR, } \\
\text { ICP-MS }\end{array}$ & {$[74]$} \\
\hline $\begin{array}{l}\mathrm{Na}_{2} \mathrm{SeO}_{3} \\
1 \mathrm{mg} / \mathrm{L}\end{array}$ & $\begin{array}{l}\mathrm{Pb}\left(\mathrm{CH}_{3} \mathrm{COO}\right)_{2} \\
350 \mathrm{mg} / \mathrm{L}\end{array}$ & $\begin{array}{l}\text { Liver } \\
\text { (in vivo) }\end{array}$ & $\begin{array}{l}\mathrm{Se} / \mathrm{Pb} \text { treatment } \\
\text { alleviated the } \\
\text { increase of mRNA } \\
\text { levels of NF-kB, } \\
\text { TNF- } \alpha, \text { COX-2, } \\
\text { PTGEs, and iNOS } \\
\text { due to Pb toxicity in } \\
\text { relation to control }\end{array}$ & $\begin{array}{l}\mathrm{Se} / \mathrm{Pb} \text { treatment } \\
\text { alleviate the } \\
\text { increase of mRNA } \\
\text { levels of HSP27, }-40, \\
-60,-70,-90 \text { caused } \\
\text { by Pb toxicity in } \\
\text { relation to control }\end{array}$ & No & No & No & qRT-PCR & {$[31]$} \\
\hline $\begin{array}{l}\mathrm{Na}_{2} \mathrm{SeO}_{3} \\
0.02 \mathrm{mg} / \mathrm{L}\end{array}$ & $\begin{array}{l}\mathrm{CdCl}_{2} \\
0.2 \mathrm{mg} / \mathrm{L}\end{array}$ & $\begin{array}{l}\text { Splenic } \\
\text { Lymphocytes } \\
\text { (in vitro) }\end{array}$ & $\begin{array}{l}\mathrm{Se} / \mathrm{Pb} \text { treatment } \\
\text { alleviated the } \\
\text { decrease of IL-1 } \beta \text {, } \\
-2,-4,-10,-17, \\
\text { and IFN- } \gamma \text { mRNA } \\
\text { levels due to Cd } \\
\text { toxicity in relation } \\
\text { to control }\end{array}$ & No & No & No & No & qRT-PCR & [44] \\
\hline
\end{tabular}


Table 1. Cont

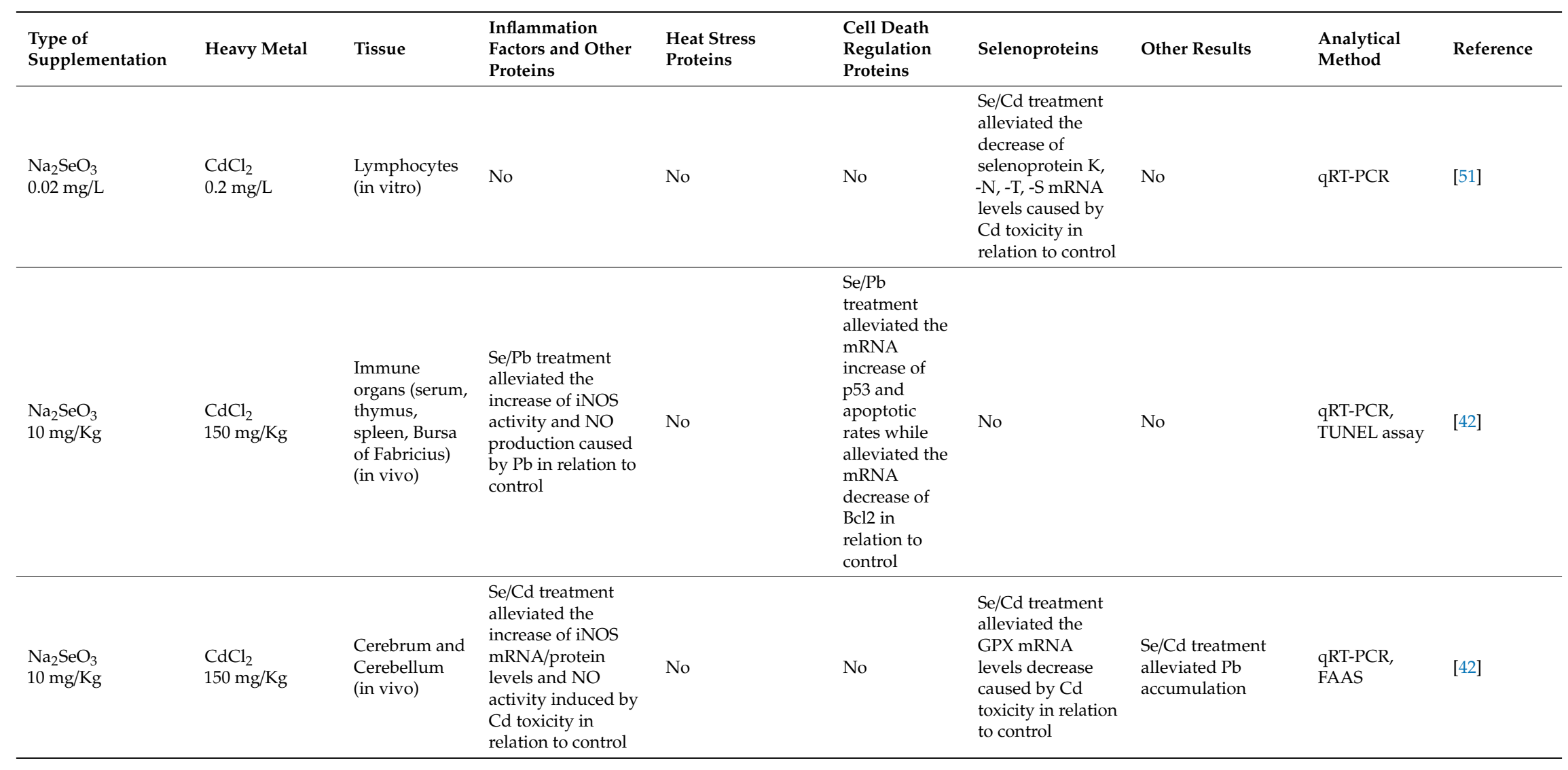


Table 1. Cont.

\begin{tabular}{|c|c|c|c|c|c|c|c|c|c|}
\hline $\begin{array}{l}\text { Type of } \\
\text { Supplementation }\end{array}$ & Heavy Metal & Tissue & $\begin{array}{l}\text { Inflammation } \\
\text { Factors and Other } \\
\text { Proteins }\end{array}$ & $\begin{array}{l}\text { Heat Stress } \\
\text { Proteins }\end{array}$ & $\begin{array}{l}\text { Cell Death } \\
\text { Regulation } \\
\text { Proteins }\end{array}$ & Selenoproteins & Other Results & $\begin{array}{l}\text { Analytical } \\
\text { Method }\end{array}$ & Reference \\
\hline $\begin{array}{l}\mathrm{Na}_{2} \mathrm{SeO}_{3} \\
0.02 \mathrm{mg} / \mathrm{L}\end{array}$ & $\begin{array}{l}\mathrm{CdCl}_{2} \\
0.2 \mathrm{mg} / \mathrm{L}\end{array}$ & $\begin{array}{l}\text { Splenic } \\
\text { Lymphocytes } \\
\text { (in vitro) }\end{array}$ & No & No & $\begin{array}{l}\text { Se/Cd } \\
\text { treatment } \\
\text { alleviated the } \\
\text { mRNA } \\
\text { increase of } \\
\text { Bak, } \\
\text { caspase-3,-9, } \\
\text { p53 and Cyt-c } \\
\text { and alleviated } \\
\text { the mRNA } \\
\text { decrease of } \\
\text { Bcl-x, Bcl-2, } \\
\text { CaM induced } \\
\text { by Cd toxicity } \\
\text { in relation to } \\
\text { control }\end{array}$ & No & No & $\begin{array}{l}\text { DCF, } \\
\text { TUNEL Assay, } \\
\text { qRT-PCR }\end{array}$ & [53] \\
\hline $\begin{array}{l}\mathrm{Na}_{2} \mathrm{SeO}_{3} \\
0.02 \mathrm{mg} / \mathrm{L}\end{array}$ & $\begin{array}{l}\mathrm{CdCl}_{2} \\
0.2 \mathrm{mg} / \mathrm{L}\end{array}$ & $\begin{array}{l}\text { Splenic } \\
\text { Lymphocytes } \\
\text { (in vitro) }\end{array}$ & No & $\begin{array}{l}\text { Se/Cd treatment } \\
\text { alleviated the } \\
\text { mRNA levels } \\
\text { increase of HSP27, } \\
-40,-60,-70,-90 \\
\text { induced by Cd } \\
\text { toxicity in relation } \\
\text { to control }\end{array}$ & No & No & No & qRT-PCR & [76] \\
\hline
\end{tabular}




\section{Heat Stress and Avian Transcriptome}

\subsection{An Overview of Heat Stress}

Regarding heat stress (HS), the poultry industry is sensitive to economic losses due to poor thermotolerance of broiler chickens [77,78]. St-Pierre et al. estimated that the livestock industry experiences a total loss of $\$ 1.7$ billion (USD) per year due to the negative effects of heat stress [77]. Heat stress has adverse impacts on a variety of performance parameters such as reduced meat quality, egg production, and feed intake of broilers [79,80]. Moreover, the above physiological imbalances of broilers, during heat stress, lead to hormonal disequilibriums [81-84] as well as decreased immune [85] and reproductive development [84].

Heat stress causes reduction of body weight gain and feed consumption [86], and is therefore a major concern for the poultry industry. Moreover, HS disrupts barrier function and affects enteric development [87]. Heat stress raises radiant heat loss through the redistribution of blood flow from the core body to the periphery. It increases also mortality and feed conversion efficiency, thus lowers carcass weight and lastly decreases broiler meat quality [88]. Moreover, it causes depletion in mineral (Se, Fe and $\mathrm{Zn}$ ) and vitamin (A and E) tissue concentrations [89] that might be a consequence of the impaired intestinal absorption, due to leakage of the gut. The decreased Se, Zn, and Fe levels outcomes in impairment of oxidative capacity [90]. The changes triggered by HS increase reactive oxygen species (ROS) formation [91-93] and interrupt the balance of antioxidant defense system and oxidation. This triggers the occurrence of lipid peroxidation and oxidative damages to biochemical molecules such as proteins and DNA [91].

Heat stress has been shown to lead to diminished growth rate in various studies [94]. Adomako et al. [95] noted that HS prompt to higher protein degradation, while both Gu et al. [96] and Li et al. [97] exhibited that HS leads to apoptosis as well. Caspase-6 constitutes a part of a gene family of caspases related to the apoptotic processes. It was observed that twelve days post-HS, CASP6 mRNA expression levels were raised, as part of a cascade developed by animals under HS to limit the accumulation of proteins. Additionally, HS results in ROS augmentation, and it seems that a concomitant raise in ROS concur with CASP6 expression to promote apoptosis [98,99]. When broilers were exposed to HS, blood and nutrient flow to gastrointestinal tract were reduced, causing ATP depletion, intestinal hypoxia, intracellular acidosis as well as nitrosative and oxidative stress together with altered intestinal integrity and function [100]. Lipopolysaccharide leakage was raised due to intestinal permeability, leading to multiple failure of organs [100].

Furthermore, meat quality was degraded under HS conditions. Poultry have increased contents of polyunsaturated fatty acids in muscles and are extremely sensitive to oxidative stress when exposed to high temperatures [101,102]. Postmortem glycolysis also rose due to oxidative stress caused by HS. Additionally, meat quality of broiler was impaired because of tissue glycogen conversion into lactic acid (protein and texture contents) [88,103,104].

Slawinska et al. [105] showed that HS environment induced iNOS activity upregulation in a chicken macrophage-like cell line. On another study [106], in contrast with common conditions, due to HS, NO content and iNOS activity were increased in the spleen of broilers. This indicated that under HS conditions, the antioxidant defense system is disrupted leading to ROS accumulation and in subsequent release of a big number of intermediaries of inflammation. Yao's research [107] demonstrated that ER stress response may be downstream from oxidative stress. Xu et al. [108] showed that under HS environment, in chicks spleen, GRP94 and GRP78 mRNA levels considerable raised which clearly indicates that ER stress occurs by HS. Also, multiple molecular pathways such as ATF6, PERK, and IRE1 have interrelation with stress in ER. During ER stress, the expression of the above genes were elevated [106]. In the next chapter, we examine in more detail the way that HS alters the avian transcriptome. 


\subsection{Avian Transcriptome Response to Heat Stress}

Heat stress alters the mRNA expression of oxidants thereby increasing cellular ROS. The NOX family is consisted of seven members (DUOX1 and -2, NOX1, -2, -3, -4, and -5] [109]. Upon the outcomes of the study by Habashy et al., some NOX enzymes encoding genes were upregulated due to long term heat stress in broilers [110]. Bánfi et al.'s [111] results demonstrated that NOX activator 1 and NOX organizer 1 (NOXO1) activate NOX1, the enzyme that generates superoxides. For instance, subunit p22phox was essential for the activation of NOX3 [112]. Although, in lack of activators, NOX3 superoxide production was raised via NOXO1 and PHOX organizers [113]. An N-terminal domain is contained in DUOX2 (like peroxidases) and DUOX2 produces hydrogen peroxide [114]. Three canonical EF-hands (calcium binding domains) are contained in N terminus of NOX5 and this differentiates it from other NADPH oxidases. In addition, superoxide is generated by NOX5 in response to intracellular $\mathrm{Ca}^{2+}$ [115].

Under $\mathrm{Ca}^{2+}$ activation, NOX5 is activated and produces high superoxide amounts and further exhibits another function by becoming a proton channel for charge compensation and $\mathrm{pH}$ changes as a result of the electron export [116]. Regarding HUVEC cells exposed to HS, cytoplasmic $\mathrm{Ca}^{2+}$ peaked $1 \mathrm{~h}$ after HS and later reduced progressively. Further, at $1 \mathrm{~h}$, a primary raise concerning mitochondrial $\mathrm{Ca}^{2+}$ was noted, which peaked at $9 \mathrm{~h}$ and reduced at $12 \mathrm{~h}$ post-HS [96]. Calcium level in chickens' plasma was increased $2 \mathrm{~h}$ post-HS but reduced to control levels, $24 \mathrm{~h}$ post-HS. In this way, it would be expected that NOX5 will be down-regulated $24 \mathrm{~h}$ post-HS as was noticed in that study. At 1 and 12 days post-HS, NOX2 was down-regulated. Presumably, NOX2 was up-regulated earlier than 1 day post-HS to produce high superoxide amounts [96]. High levels of superoxide have been exhibited to up-regulate the SOD expression $[117,118]$. It may be assumed that SOD up-regulation may lead to NOX2 down-regulation [119]. Corresponding to NOX5, NOX2 regulation may involve other factors apart from ROS. Reports demonstrated that HS-induced small ubiquitin-like modifier 1 (SUMO1) down-regulates ROS production through NOX2 [120]. This may clarify the negative NOX2 regulation upon HS.

In addition, SODs are ubiquitous enzymes catalyzing the superoxide anions' dismutation to hydrogen peroxide. SOD1 (cytoplasmic isoform) and SOD3 (extracellular isoform) contain Cu and $\mathrm{Zn}$, whereas SOD2, the mitochondrial isoform, has $\mathrm{Mn}$ in its reactive site [121]. In another study, Habashy et al. [110] noticed that the SOD1 mRNA expression did not alter 1 day post-HS, but raised at 12 days post-HS. Particular functions between SODs may be the result of subcellular location [121]. Notwithstanding, it is obvious that birds' HS exposure results to mRNA expression alterations in NADPH oxidases that induce SOD1 up-regulation, one of the pivotal enzymatic antioxidant defenses as regards cell damages by superoxide anions. As reported by Schafer and Buettner [122] superoxide dismutase up-regulation is one of the mechanisms cells employ to control potential cytotoxicity induced by stress. These results were in accordance with Azad et al.'s [123] results, which described that cytoplasmic $\mathrm{Cu} / \mathrm{Zn}-\mathrm{SOD}$ (SOD1) activity raised in the Pectoralis major muscle after chronic exposure of chickens to HS.

Differently, through the antioxidant enzyme catalase (CAT), $\mathrm{H}_{2} \mathrm{O}_{2}$ is converted to water and oxygen, and through GPX, $\mathrm{H}_{2} \mathrm{O}_{2}$ is converted to water in a reaction, oxidizing GSH to its disulfide form (GSSG). Glutathione is regenerated from GSSG by GR. Data concerning the regulation of CAT, GPX, NADPH, and GR in both acute and chronic HS is insufficient. The GPX, CAT, and NADPH genes were negatively regulated at 1 day post-HS, presumably as a result of $\mathrm{H}_{2} \mathrm{O}_{2}$ raise. It has been demonstrated that exhibition to ROS negatively regulated CAT expression through hypermethylation of a CpG island in CAT promoter [124,125]. The high levels of cellular $\mathrm{H}_{2} \mathrm{O}_{2}$ due to $\mathrm{HS}$ may have caused the negative regulation of GPX and CAT. This may be true not only at gene level, since in case of GPX, post-translational modifications have been reported irrespective of changes at gene expression levels [126].

Niu et al. [127] showed that S-glutahionylation of human cystathionine $\beta$-synthase increased its activity to enhance the production of cysteine and afterwards GSH under oxidative stress conditions. 
Recently, Habashy et al. [128] exhibited that under HS, cysteine is mainly incorporated into chickens' tissues compared to any other amino acid. Under HS, dietary methionine (a cysteine precursor) should be raised to increase the trans-sulfuration pathway flux in order to convert homocysteine to cysteine. In another study, Eriksson et al. [129] exhibited that methionine is critical in reduction systems and cells protection against oxidative stress through an NADPH-independent pathway. It was exhibited that hepatocytes can preserve cytosolic redox homeostasis by utilizing NAPDH or methionine. Nrf2 gene was slightly negatively regulated at 1 day post-HS, but not at 12 days post-HS.

The induction of NADPH and GST by electrophiles and antioxidants has been shown to be mediated by the activation of Nrf2 in human [130]. It should be also noticed that GST was positively regulated at 1 day post-HS, which commonly believed to accelerate the conjugations between GSH and 4-hydroxynonenal (HNE), a byproduct of lipid peroxidation generated upon HS [131]. GST negative regulation 12 days post-HS may be a result of GSH depletion. Further, Nrf2 activates the antioxidant responsive elements which induce the transcription of diverse genes in the redox homeostasis machinery [132]. Presumably, the early transcriptional alteration in Nrf2 during HS is essential to trigger a cascade of events to reserve redox homeostasis [110].

Al-Zghoul et al. in their experiment on thermal manipulated (TM) chicks illustrated that levels of SOD2, GPX2, NOX4, and CAT expression were significantly lower in the TM groups in two chicken breeds (Hubbard and Cobb) [133]. This demonstrates that the reduction of NOX4 expression in the TM groups alleviates oxidative stress by decreasing NOX-induced ROS. Additionally, AvUcp expression levels in the Hubbard and Cobb TM groups generally increased after exposure to acute heat stress (AHS) compared to controls. These results indicate that TM through raising AvUcp mRNA levels has a positive effect on ROS reduction. In relation with the above results, TM treatment has a role in decreasing heat-induced oxidative stress, the latter of which can be ascertained by the reduction and elevation of NOX4 and AvUcp mRNA levels, respectively. Lastly, they showed that TM directs thermotolerance acquisition in broiler chicken and indicated considerable differences among breeds [133].

Moreover, the relative mRNAs expression of $\operatorname{HSP}(60,70$, and 90) in the heart of broiler chickens were significantly elevated after exposure to $\mathrm{HS}$ for $2 \mathrm{~h}$ and then declined rapidly with further exposure. In addition, the up-regulation of these stress proteins in heart act as important biomarkers and protective proteins at the start of HS [102]. A summary of selected studies in chicken reporting the effects of heat stress on various factors, HSP, and selenoproteins is shown in Table 2. 
Table 2. A summary of selected studies in chicken reporting effects of heat stress on various factors, HSP, and selenoproteins.

\begin{tabular}{|c|c|c|c|c|c|c|c|}
\hline $\begin{array}{l}\text { Type of } \\
\text { Supplementation }\end{array}$ & Tissue & Selenoproteins & Heat Stress Proteins & Antioxidant Capacity & Other Results & $\begin{array}{l}\text { Analytical } \\
\text { Techniques/Methods }\end{array}$ & References \\
\hline $\begin{array}{l}\mathrm{Na}_{2} \mathrm{SeO}_{3} \\
0.2 \mathrm{mg} / \mathrm{Kg}, \\
\text { Vit E } \\
250 \mathrm{mg}\end{array}$ & Breast muscles & $\begin{array}{l}\text { Se/Vit E: } \\
\text { upregulation of } \\
\text { Gpx1, Gpx4 and } \\
\text { selenoprotein P in } \\
\text { relation to control } \\
\text { and Se group }\end{array}$ & $\begin{array}{l}\text { HSP60, -70, }-90 \text { small } \\
\text { mRNA decrease in Se } \\
\text { group, no differences in } \\
\text { Se/Vit E group }\end{array}$ & $\begin{array}{l}\text { Se/Vit E and Se group: } \\
\text { increase in concentration of } \\
\text { CAT, SOD, GSH-P and } \\
\text { MDA especially in Se/Vit E } \\
\text { group in relation to control }\end{array}$ & & RT-PCR & [134] \\
\hline $\begin{array}{l}\text { BET } \\
1 \mathrm{~g} / \mathrm{Kg}, \\
\text { Vit E } \\
250 \mathrm{mg} / \mathrm{Kg}, \\
\mathrm{Se} \\
0.8 \mathrm{mg} / \mathrm{Kg}\end{array}$ & Breast muscle & & & $\begin{array}{l}\text { BET, Vit } E \text { and Se: increased } \\
\text { GPx activity }\end{array}$ & $\begin{array}{l}\text { BET reduced } \\
\text { respiratory rate }\end{array}$ & GPx Assay & [135] \\
\hline No & Liver & $\begin{array}{l}\text { Gpx1 mRNA } \\
\text { decrease }\end{array}$ & & $\begin{array}{l}\text { Heat stress treatment: } \\
\text { increase NOX1, NOX3, } \\
\text { DUOX2, GST, CAT, SOD1, } \\
\text { GR, CASP6 mRNAs and } \\
\text { decrease of CYBB, NOX4, } \\
\text { NOX5, NADPH mRNAs }\end{array}$ & & RT-PCR & [110] \\
\hline $\begin{array}{l}\mathrm{Na}_{2} \mathrm{SeO}_{3} \\
0.30 \mathrm{mg} / \mathrm{Kg}, \\
\text { Se-yeast } \\
0.30 \mathrm{mg} / \mathrm{Kg}\end{array}$ & Breast muscles & $\begin{array}{l}\text { upregulation of } \\
\text { Gpx1, Gpx4 in } \\
\text { both Se treatments }\end{array}$ & $\begin{array}{l}\text { Downregulation of HSP70 } \\
\text { in inorganic Se group, } \\
\text { Se-yeast group showed a } \\
\text { further downregulation } \\
\text { HSP70 mRNA levels } \\
\text { compared to control and } \\
\text { inorganic Se group }\end{array}$ & & $\begin{array}{l}\text { Improved } \\
\text { organoleptic meat } \\
\text { characteristics } \\
\text { (meat drip loss, } \\
\text { water holding } \\
\text { capacity, and shear } \\
\text { force) }\end{array}$ & $\begin{array}{l}\text { qRT-PCR, } \\
\text { HG-AFS }\end{array}$ & [136] \\
\hline
\end{tabular}


Table 2. Cont

\begin{tabular}{|c|c|c|c|c|c|c|c|}
\hline $\begin{array}{l}\text { Type of } \\
\text { Supplementation }\end{array}$ & Tissue & Selenoproteins & Heat Stress Proteins & Antioxidant Capacity & Other Results & $\begin{array}{l}\text { Analytical } \\
\text { Techniques/Methods }\end{array}$ & References \\
\hline $\begin{array}{l}\text { Nano-selenium } \\
1.2 \mathrm{mg} / \mathrm{Kg}\end{array}$ & Jejunal tissue & & & & $\begin{array}{l}\text { Decreased the } \\
\text { plasma } \\
\text { concentrations of } \\
\text { LDL-C and AST, } \\
\text { but linearly } \\
\text { increased that of } \\
\text { HDL-C before heat } \\
\text { exposure. } \\
\text { Moreover, } \\
\text { the cholesterol } \\
\text { concentration was } \\
\text { lower in broilers } \\
\text { fed diets } \\
\text { supplemented } \\
\text { with } 0.6 \text { mg/kg } \\
\text { Nano-Se than that } \\
\text { in the control ones. } \\
\text { Heat stress } \\
\text { decreased the } \\
\text { plasma total } \\
\text { protein } \\
\text { concentration, but } \\
\text { increased the AST } \\
\text { activity }\end{array}$ & Enzymatic Kits & [137] \\
\hline $\begin{array}{l}\text { Vit A } 16.000 \mathrm{IU} / \mathrm{kg} \text {, } \\
\mathrm{Na}_{2} \mathrm{SeO}_{3} \\
0.50 \mathrm{mg} / \mathrm{kg}\end{array}$ & & & & & $\begin{array}{l}\text { Se/Vit E group: no } \\
\text { significant change } \\
\text { in egg quality in } \\
\text { relation to control } \\
\text { but significant } \\
\text { changes in hen } \\
\text { performance }\end{array}$ & & [138] \\
\hline $\begin{array}{l}\text { DL- } \alpha \text {-tocopherole } \\
\text { acetate } \\
500 \mathrm{mg} / \mathrm{Kg} \text {, } \\
\mathrm{Na}_{2} \mathrm{SeO}_{3} \\
0.5 \mathrm{mg} / \mathrm{Kg}\end{array}$ & & & & & $\begin{array}{l}\text { Se/Vit E group: } \\
\text { synergistic effect } \\
\text { between Se and Vit } \\
\text { E in alleviation of } \\
\text { heat stress }\end{array}$ & & [139] \\
\hline
\end{tabular}


Table 2. Cont.

\begin{tabular}{|c|c|c|c|c|c|c|c|}
\hline $\begin{array}{l}\text { Type of } \\
\text { Supplementation }\end{array}$ & Tissue & Selenoproteins & Heat Stress Proteins & Antioxidant Capacity & Other Results & $\begin{array}{l}\text { Analytical } \\
\text { Techniques/Methods }\end{array}$ & References \\
\hline $\begin{array}{l}\mathrm{Na}_{2} \mathrm{SeO}_{3} \\
1.5 \mathrm{mg} / \mathrm{Kg} \\
\mathrm{PAMK} \\
200 \mathrm{mg} / \mathrm{Kg}\end{array}$ & Spleen & & $\begin{array}{l}\text { Alleviation of increase of } \\
\text { mRNA expression of } \\
\text { HSP90, GRP-78 caused by } \\
\text { heat stress }\end{array}$ & & $\begin{array}{l}\text { Se/PAMK group: } \\
\text { alleviation of } \\
\text { increase of } \\
\text { expression of Bcl-2, } \\
\text { caspase-3, ATF4, } \\
\text { ATF6, IRE due to } \\
\text { heat stress }\end{array}$ & $\begin{array}{l}\text { qRT-PCR, } \\
\text { Western Blot }\end{array}$ & [106] \\
\hline $\begin{array}{l}\text { Organic Se } \\
0.3 \mathrm{mg} / \mathrm{Kg}, \\
\mathrm{Cr} 2 \mathrm{mg} / \mathrm{Kg}, \\
\mathrm{Zn} 40 \mathrm{mg} / \mathrm{Kg}\end{array}$ & Blood & & & $\begin{array}{l}\text { Improved performance and } \\
\text { antioxidant responses } \\
\text { (reduced LP and increased } \\
\text { superoxide dismutase) }\end{array}$ & & & [140] \\
\hline $\begin{array}{l}\text { SeMet } 1 \mathrm{mg} / \mathrm{Kg} \\
\alpha \text {-tocopherol } \\
\text { acetate } 250 \mathrm{mg} / \mathrm{Kg}\end{array}$ & Breast & & & & $\begin{array}{l}\text { Se/Vit E group: } \\
\text { growth } \\
\text { performance was } \\
\text { not improved but } \\
\text { improved lipid } \\
\text { oxidation of breast } \\
\text { meat }\end{array}$ & $\begin{array}{l}\text { AAS, } \\
\text { MDA determination }\end{array}$ & [141] \\
\hline $\begin{array}{l}\text { Se } \\
3 \mathrm{mg} / \mathrm{Kg}, \\
\mathrm{PAMK} \\
200 \mathrm{mg} / \mathrm{Kg}\end{array}$ & $\begin{array}{l}\text { Bursa of Fabricius, } \\
\text { spleen, thymus }\end{array}$ & & $\begin{array}{l}\text { Se/PAMK: Improved } \\
\text { alleviation of mRNA } \\
\text { increase of HSP60, -70, }-90\end{array}$ & & $\begin{array}{l}\text { Se/PAMK group: } \\
\text { Alleviation of } \\
\text { mRNA increase of } \\
\text { TNF-a, IFN- } \gamma \text {, IL2 } \\
\text { and IL4 caused by } \\
\text { heat stress }\end{array}$ & qRT-PCR & [142] \\
\hline $\begin{array}{l}\text { Se } \\
3 \mathrm{mg} / \mathrm{Kg}, \\
\mathrm{PAMK} \\
200 \mathrm{mg} / \mathrm{Kg} \\
\end{array}$ & $\begin{array}{l}\text { Endoplasmic } \\
\text { reticulum of } \\
\text { Spleen tissue }\end{array}$ & & $\begin{array}{l}\text { Higher alleviation of } \\
\text { HSP27 and -70 increase in } \\
\text { Se/PAMK group }\end{array}$ & & & $\begin{array}{l}\text { qRT-PCR, Western } \\
\text { Blot Analysis }\end{array}$ & [108] \\
\hline $\begin{array}{l}\text { Se } \\
1 \mathrm{mg} / \mathrm{Kg} \text {, } \\
\text { Vit E } \\
250 \mathrm{mg} / \mathrm{Kg}\end{array}$ & & & & & $\begin{array}{l}\text { Better immune } \\
\text { responses }\end{array}$ & Enzymatic methods & [143] \\
\hline
\end{tabular}


Table 2. Cont.

\begin{tabular}{|c|c|c|c|c|c|c|c|}
\hline $\begin{array}{l}\text { Type of } \\
\text { Supplementation }\end{array}$ & Tissue & Selenoproteins & Heat Stress Proteins & Antioxidant Capacity & Other Results & $\begin{array}{l}\text { Analytical } \\
\text { Techniques/Methods }\end{array}$ & References \\
\hline $\begin{array}{l}\mathrm{Na}_{2} \mathrm{SeO}_{3} \\
0.028 \mathrm{mg} / \mathrm{Kg}\end{array}$ & $\begin{array}{l}\text { Liver, Breast } \\
\text { muscle }\end{array}$ & & & $\begin{array}{l}\text { GSH-Px activity increase } \\
\text { due to Se supplementation }\end{array}$ & & Enzymatic methods & [144] \\
\hline $\begin{array}{l}\text { Vit E } \\
250 \mathrm{mg} / \mathrm{kg}, \\
\mathrm{Se} \\
1 \mathrm{mg} / \mathrm{kg}\end{array}$ & Pectoralis muscle & & & $\begin{array}{l}\text { SOD and Gpx activity } \\
\text { increase }\end{array}$ & $\begin{array}{l}\text { There was not a } \\
\text { significant } \\
\text { interaction in } \\
\text { broiler growth } \\
\text { performance } \\
\text { between dietary } \\
\text { treatments and } \\
\text { environmental } \\
\text { temperature }\end{array}$ & Enzymatic methods & [145] \\
\hline $\begin{array}{l}\text { Se } \\
0.3 \mathrm{~g} / \mathrm{Kg}, \\
\mathrm{TP} \\
10 \mathrm{~g} / \mathrm{Kg}\end{array}$ & Blood & & & & $\begin{array}{l}\text { Se/TP significantly } \\
\text { reduced plasma } \\
\text { triglycerides no } \\
\text { significant effects } \\
\text { on plasma } \\
\text { hormones T }\end{array}$ & Enzymatic Methods & [146] \\
\hline
\end{tabular}




\subsection{Antioxidant Supplements during Heat Stress and Avian Antioxidant Transcriptome Response}

Several nutritional approaches, such as supplementation of diets with phytochemicals, have been used in attempts to attenuate the negative effects of HS [147]. Vitamin E (Vit E) is a fat-soluble vitamin with antioxidant properties [148] that regenerates damaged tissues [149,150] during oxidative stress by participating in the GPX pathway causing enhanced chicken performance [151].

Furthermore, Vit E and Se combined supplementation proved to be the most effective inhibitor of lipid peroxidation. Dietary Vit E and Se supplementation led to significant increases in SOD and CAT levels in breast muscle of heat-stressed broilers. Selenium alongside with Vit $\mathrm{E}$ had a synergistic effect on SOD, GPX, and CAT activity. However, Shahnawaz Kumbhar showed that enzyme activity of GPX remained depressed in case of dietary Vit E [134]. Furthermore, MDA content in breast meat decreased by both Se and Vit E supplementation under HS condition [141]. That was in agreement with other findings, who observed a significant increase in tissue GPX1, GPX4, and selenoprotein P mRNA levels when broilers were fed Se and Se+Vit E supplemented diets. However, no effect on these indices was recorded in broilers given the Vit E supplemented diet.

Selenium performs its biological functions mainly through selenoproteins, as Se is mainly incorporated in selenoproteins' active sites [152]. Selenoproteins like GPX1, GPX4, and selenoprotein P play vital roles in a variety of biological processes by participating in the antioxidant defense system. Different Se forms including inorganic, such as sodium selenite, organic, such as Se-enriched yeast, and nanoselenium (Nano-Se) have been compared to choose the best source of Se for maximizing the poultry production and health in oxidative or thermoneutral rearing conditions [102].

Thus, Nano-Se supplementation has been proposed for reduction of HS effects in broilers. In a study on the effects of dietary Nano-Se supplementation at 0.6 and $1.2 \mathrm{mg} / \mathrm{kg}$ of diet on growth performance, serum biochemical parameters, immune response, antioxidant capacity, and jejunal morphology of 29-d-old male broilers subjected to HS at $37 \pm 1{ }^{\circ} \mathrm{C}$ for $14 \mathrm{~d}$, it has been shown that heat-stressed broilers had lower FI and BMG, but higher FCR than those kept in thermoneutral condition. According to Safdari-Rostamabad's [137] study outcomes in broilers after 48 days of HS exposure, FCR of broilers improved due to dietary supplementation with $1.2 \mathrm{mg} / \mathrm{kg}$ Nano-Se. Furthermore, the $1.2 \mathrm{mg} / \mathrm{kg}$ Nano-Se supplementation had better results than the $0.6 \mathrm{mg} / \mathrm{kg}$ or the control treatment concerning FCR and BMG, proposing that heat-stressed broilers' performance can be improved with a supplementation rate of $1.2 \mathrm{mg} / \mathrm{kg}$. This might be associated to HSPs (and other chaperones) and to proteolytic enzymes.

Hu et al. [153], compared the effects of Nano-Se and sodium selenite on the growth performance of broilers, Se concentrations in liver, serum, and breast muscle, activity GPX in serum, and retention of Se in the whole body and in liver tissue. It was showed that both Se sources comparably increased feed efficiency, average daily gain, survival ratio, and serum GPX activity. Nevertheless, Nano-Se supplementation in broilers notably improved Se transfer to the body from intestinal lumen, Se concentration in tissues and in the serum and retention of Se in the whole body. Also, performance parameters were not affected by different Se supplementation sources (Nano-Se, Se-enriched yeast and sodium selenite) in the non-stressed or oxidative-stressed broilers. However, Nano-Se triggered the most noticeable impact in oxidative stressed broilers [154]. In parallel with the above outcomes, Safdari-Rostamabad et al. demonstrated that during broilers' grower and starter phases, Nano-Se supplementation at levels of 0.6 or $1.2 \mathrm{mg} / \mathrm{kg}$ had no beneficial effect [137]. Also, Nano-Se supplementation did not alleviate the adverse effect of HS on pancreas [137]. On the other hand, supplementation with Se enriched probiotics, facilitated an induction of the endogenous antioxidant defense system. These observations indicate that an improved antioxidant status could greatly attenuate heat-stress-induced HSPs expression.

In another study, when broilers were supplemented with Se enriched prebiotics (SP), a significant downregulation was observed in the expression of the HSPs $(60,70$, and 90) heat stress biomarkers in the breast muscles of each experimental group compared with the control group. The SP group had a profound effect on decreasing the HSP70 mRNA levels in comparison to control [136]. 


\section{Bibliometric Evaluation}

The field of selenoprotein transcriptome in chicken and its interactions with heavy metals has recently been attracting more and more research interest (Figure 1). The search was performed using Scopus database and [TITLE-ABS-KEY(("selenium supplementation" OR selenium OR selenoproteins OR DIO1 OR "iodothyronine deiodinase 1" OR DIO2 OR "iodothyronine deiodinase 2" OR DIO3 OR "iodothyronine deiodinase 3" OR GPX1 OR "glutathione peroxidase 1" OR GPX2 OR "glutathione peroxidase 2" OR GPX3 OR "glutathione peroxidase 3" OR GPX4 OR "glutathione peroxidase 4" OR GPX6 OR "glutathione peroxidase 6" OR MRSB1 OR "methionine sulfoxide reductase B1" OR selenof OR "selenoprotein F" OR selenoh OR "Selenoprotein H" OR selenoi OR "selenoprotein I" OR selenok OR "selenoprotein K" OR selenom OR "selenoprotein M" OR selenon OR "selenoprotein N" OR selenoo OR "selenoprotein O" OR selenop1 OR "selenoprotein P1" OR selenop2 OR "selenoprotein P2" OR selenos OR "selenoprotein S" OR selenot OR "selenoprotein T" OR selenou OR "selenoprotein U" OR selenov OR "selenoprotein V" OR selenow OR "selenoprotein W" OR sephs2 OR "selenophosphate synthetase 2" OR TXNRD1 OR "thioredoxin reductase 1" OR TXNRD2 OR "thioredoxin reductase 2" OR TXNRD3 OR "thioredoxin reductase 3") AND (Cd OR cadmium OR chromium OR Cr OR mercury OR Hg OR arsenic OR As OR lead OR Pb OR "heavy metals" OR "toxic elements") AND (chicken OR chick OR chicks OR broiler OR hen OR egg) AND (mRNA OR transcriptome OR transcript OR RNA))] were used as keywords. Figure 1 shows the temporal evolution of the articles. As it is shown, there has been an exponential growth in the last 10 years. Related articles were more than 70 in the period 2016-2018 whereas in the period 2007-2009 were only 4. Authors anticipate that this trend will continue in the next years.

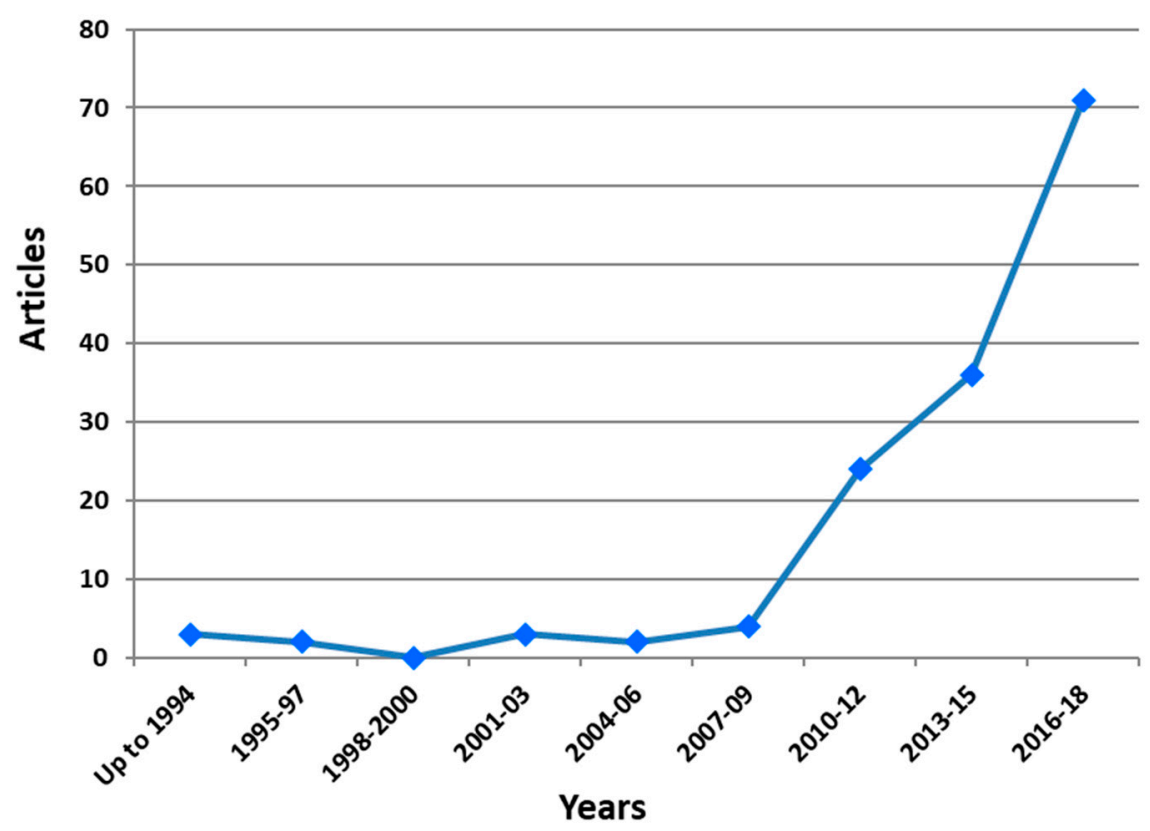

Figure 1. Temporal evolution of articles concerning selenoprotein transcriptome in chicken and its interactions with heavy metals.

Figure 2 shows the related research per country. China outnumbers all other countries, obtaining more than $50 \%$ of the total with 105 articles. As it is known, China is one of the greatest producers of plant protection products and fertilizers. These products could include heavy metals. Further, China has a high number of industries that could use or have as by-products heavy metals. Moreover, China's GPD increases continuously and so more and more research is conducted. Another reason why most articles come from China is that the health issue of Keshan's disease emerged, a congestive cardiomyopathy caused by a combination of dietary deficiency of Se and the presence of a mutated strain of Coxsackievirus. These symptoms were prevalent in a wide area extending from north-east 
to south-west China, all due to Se-deficient soil. The U.S. is in the second position with 29 articles, and South Korea, Belgium, Pakistan, and other countries follow. Articles are scattered in more than 60 journals. This fact could be explained due to the multidisciplinary character of the field. Although, "Biol. Trace Elem. Res." dominates the field with 49 articles, while "Environ. Sci. Pollut. Res." and "Poult. Sci." are following with 6 articles each. These journals are highly cited, reflecting the importance of the field.

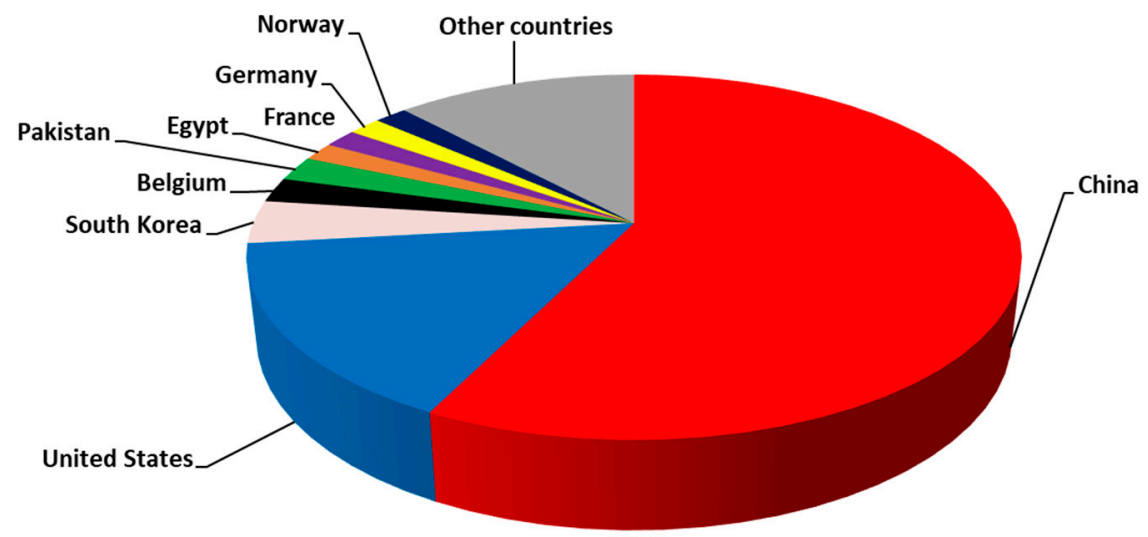

Figure 2. Articles per country, concerning selenoprotein transcriptome in chicken and its interactions with heavy metals.

Regarding research on selenoprotein transcriptome in chicken and its adaptation to HS and Se deficiency, the number of articles has also an increasing trend (Figure 3). The search was performed using Scopus database and TITLE-ABS-KEY[(“"selenium supplementation" OR selenium OR selenoproteins OR DIO1 OR "iodothyronine deiodinase 1" OR DIO2 OR "iodothyronine deiodinase 2" OR DIO3 OR "iodothyronine deiodinase 3" OR GPX1 OR "glutathione peroxidase 1" OR GPX2 OR "glutathione peroxidase 2" OR GPX3 OR "glutathione peroxidase 3" OR GPX4 OR "glutathione peroxidase 4" OR GPX6 OR "glutathione peroxidase 6" OR MRSB1 OR "methionine sulfoxide reductase B1" OR selenof OR "selenoprotein F" OR selenoh OR "Selenoprotein H" OR selenoi OR "selenoprotein I" OR selenok OR "selenoprotein K" OR selenom OR "selenoprotein M" OR selenon OR "selenoprotein N" OR selenoo OR "selenoprotein O" OR selenop1 OR "selenoprotein P1" OR selenop2 OR "selenoprotein P2" OR selenos OR "selenoprotein S" OR selenot OR "selenoprotein T" OR selenou OR "selenoprotein U" OR selenov OR "selenoprotein V" OR selenow OR "selenoprotein W" OR sephs2 OR "selenophosphate synthetase 2" OR TXNRD1 OR "thioredoxin reductase 1" OR TXNRD2 OR "thioredoxin reductase 2" OR TXNRD3 OR "thioredoxin reductase 3") AND (chicken OR chick OR chicks OR broiler OR hen OR egg) AND ("heat stress"))] were used as keywords. The number of related articles were more than doubled in last 3-year period (2016-2018). As depicted in Figure 3, 58 articles have been published until the end of 2018. Half of them were published after 2013. 


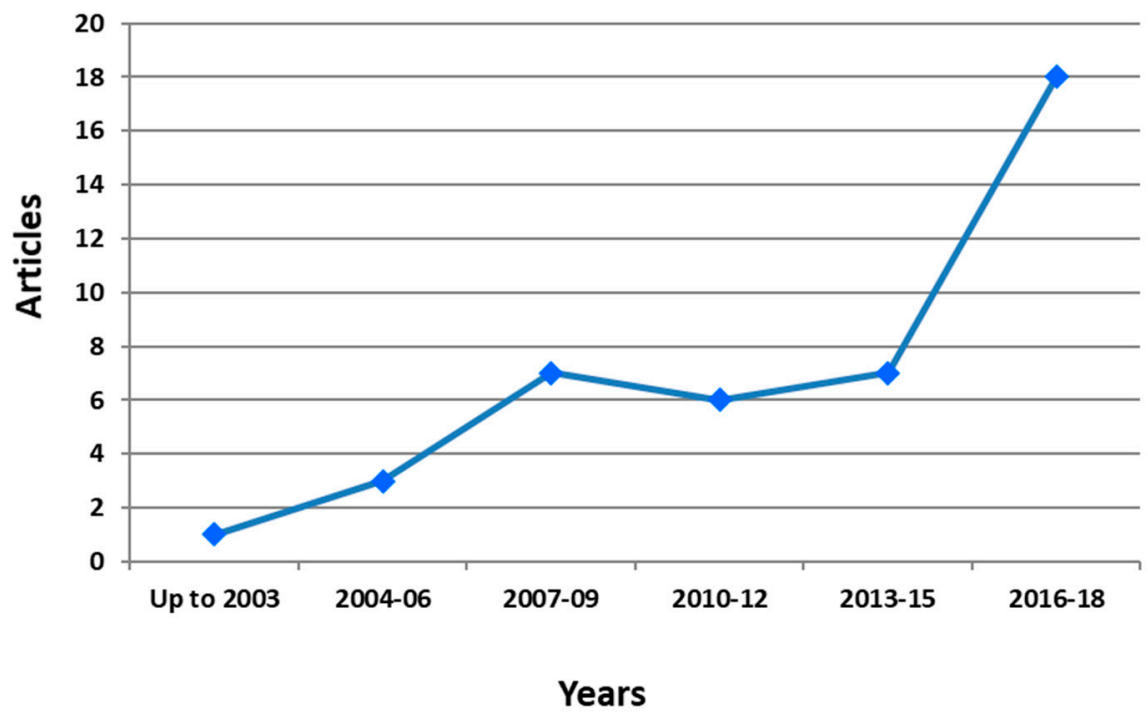

Figure 3. Temporal evolution of articles concerning selenoprotein transcriptome in chicken and its adaptation to heat stress and selenium deficiency.

Figure 4 includes the countries which have published relative articles. Asian countries dominate the field. Particularly, China is again in the first place with 13 articles. Brazil, Egypt, and Iran follow with 8 articles each, and Pakistan and United States with 5 articles each. These countries are known for their warm climate and usually hot summers. Meanwhile, there is high demand for chicken meat in these countries. Therefore, the production of chicken is analogous. With regard to journals, "Biol. Trace Elem. Res." leads with 11 articles.

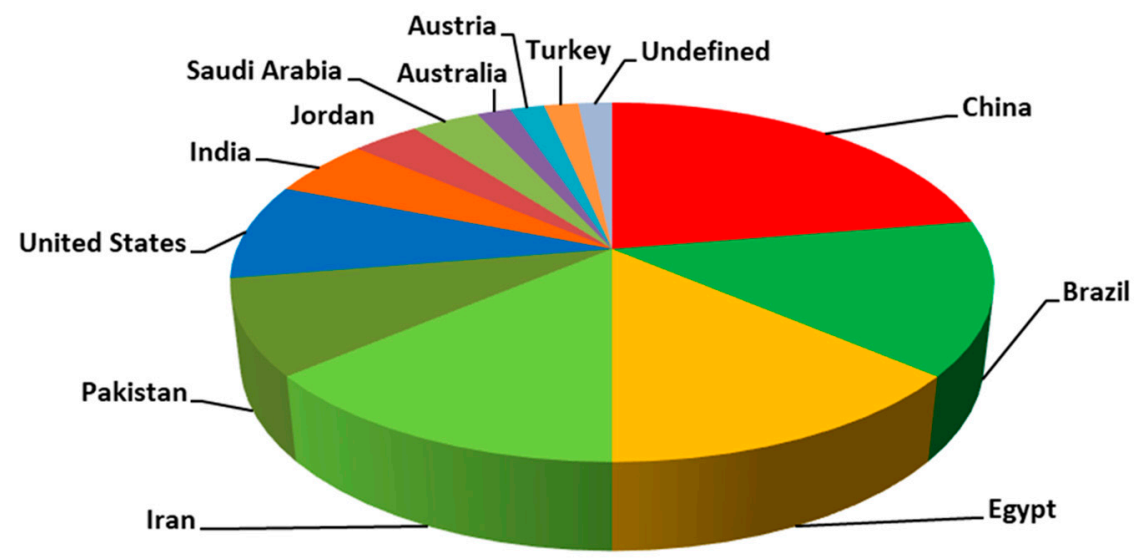

Figure 4. Articles per country, concerning selenoprotein transcriptome in chicken and its adaptation to heat stress and selenium deficiency.

\section{Conclusions}

It can be concluded that the toxic effects of $\mathrm{Cd}$ and $\mathrm{Pb}$ and the harmful effects caused by heat stress in chickens are alleviated via supplementation of Se. Studies highlight selenium's role as antioxidant and modulator for the enzymatic and non-enzymatic antioxidant defense factors such as GSH, GPx, and TrxR in order to modulate the toxic effects of heavy metals in chicken. Further, Se alleviates the excess of mRNA expression levels of apoptotic factors, immune proteins, and heat stress proteins caused by heavy metals. In addition, over heat stress conditions, Se through upregulation of GPxs and other selenoproteins, eliminates heat stress proteins mRNA levels in many chicken tissues and reduces mRNA increase of inflammatory factors and other chicken immune responses. 
Author Contributions: All authors contributed equally to the completion of this paper. E.Z. and I.S. conceived the idea and contributed to manuscript writing, analysis, and review; A.C.P. and G.P.D. collected sources of information and contributed to the manuscript writing; K.F. coordinated the project and reviewed the manuscript. All authors read and approved the final manuscript.

Funding: This research received no external funding.

Conflicts of Interest: The authors declare no conflict of interest.

\section{Abbreviations}

\begin{tabular}{ll} 
ATF4 & Activating transcription factor 4 \\
AvUcp & Avian uncoupling protein \\
Bak & BCL2 antagonist/killer 1 \\
Bcl-2 & B-cell lymphoma 2 gene \\
Bcl-xL & B-cell lymphoma-extra large \\
BNIP3 & Adenovirus E1B 19 kDa protein-interacting protein 3 \\
CaM & Calmodulin protein gene \\
CHOP & CCAAT-enhancer-binding protein homologous protein \\
COX-2 & Cyclooxygenase 2 \\
DIO & Iodothyronine deiodinase \\
eIF2 $\alpha$ & Eukaryotic Initiation Factor 2 \\
GPX & Glutathione peroxidase \\
GRP78 & Unfolded protein response regulator \\
GSH & Glutathione \\
GST & Glutathione S-transferases \\
ICAM-1 & Intercellular Adhesion Molecule 1 \\
IFN- $\gamma$ & Interferon gamma \\
IL & Interleukin \\
iNOS & Inducible NO synthase \\
NF-kB & Nuclear factor kappa-light-chain-enhancer of activated B cells \\
NO & Nitric oxide \\
p53 & Tumor protein p53 gene \\
PERK & Protein kinase RNA-like endoplasmic reticulum kinase \\
PGE2 & Prostaglandin E2 \\
PTGES & prostaglandin E synthase \\
SECIS & Selenocysteine insertion sequence \\
SEPHS2 & Selenophosphate Synthetase 2 gene \\
SEPP1 & Selenoprotein P \\
Sepx1 & Methionine-R-sulfoxide reductase B1 \\
SOD & Superoxide dismutase \\
TGF- $\beta 4$ & Transforming Growth Factor- $\beta$ \\
TNF- $\alpha$ & Tumor necrosis factor alfa \\
TNR- $\alpha$ & Tumor necrosis receptor alfa \\
TXNRD & Thioredoxin reductase \\
\hline
\end{tabular}

\section{References}

1. Schomburg, L.; Schweizer, U.; Köhrle, J. Selenium and selenoproteins in mammals: Extraordinary, essential, enigmatic. Cell. Mol. Life Sci. 2004, 61, 1988-1995. [CrossRef] [PubMed]

2. Papp, L.V.; Lu, J.; Holmgren, A.; Khanna, K.K. From selenium to selenoproteins: Synthesis, identity, and their role in human health. Antioxid. Redox Signal. 2007, 9, 775-806. [CrossRef] [PubMed]

3. Peng, A.; Wang, W.-H.; Wang, C.-X.; Wang, Z.-J.; Rui, H.-F.; Wang, W.-Z.; Yang, Z.-W. The role of humic substances in drinking water in Kashin-Beck disease in China. Environ. Health Perspect. 1999, 107, 293. [CrossRef] [PubMed]

4. Labunskyy, V.M.; Hatfield, D.L.; Gladyshev, V.N. Selenoproteins: Molecular pathways and physiological roles. Physiol. Rev. 2014, 94, 739-777. [CrossRef] [PubMed] 
5. Böck, A.; Forchhammer, K.; Heider, J.; Leinfelder, W.; Sawers, G.; Veprek, B.; Zinoni, F. Selenocysteine: The 21st amino acid. Mol. Microbiol. 1991, 5, 515-520. [CrossRef] [PubMed]

6. Zinoni, F.; Birkmann, A.; Leinfelder, W.; Böck, A. Cotranslational insertion of selenocysteine into formate dehydrogenase from Escherichia coli directed by a UGA codon. Proc. Natl. Acad. Sci. USA 1987, 84, 3156-3160. [CrossRef] [PubMed]

7. Chambers, I.; Frampton, J.; Goldfarb, P.; Affara, N.; McBain, W.; Harrison, P.R. The structure of the mouse glutathione peroxidase gene: The selenocysteine in the active site is encoded by the 'termination'codon, TGA. EMBO J. 1986, 5, 1221-1227. [CrossRef] [PubMed]

8. Bo, A.; Forchhammer, K.; Heider, J.; Baron, C. Selenoprotein synthesis: An expansion of the genetic code. Trends Biochem. Sci. 1991, 16, 463-467.

9. Berry, M.J.; Banu, L.; Chen, Y.; Mandel, S.J.; Kieffer, J.D.; Harney, J.W.; Larsen, P.R. Recognition of UGA as a selenocysteine codon in type I deiodinase requires sequences in the $3^{\prime}$ untranslated region. Nature 1991, 353, 273. [CrossRef]

10. Xu, J.; Wang, L.; Tang, J.; Jia, G.; Liu, G.; Chen, X.; Cai, J.; Shang, H.; Zhao, H. Pancreatic atrophy caused by dietary selenium deficiency induces hypoinsulinemic hyperglycemia via global down-regulation of selenoprotein encoding genes in broilers. PLoS ONE 2017, 12, e0182079. [CrossRef]

11. Thompson, J.; Scott, M. Role of selenium in the nutrition of the chick. J. Nutr. 1969, 97, 335-342. [CrossRef] [PubMed]

12. Huang, J.-Q.; Li, D.-L.; Zhao, H.; Sun, L.-H.; Xia, X.-J.; Wang, K.-N.; Luo, X.; Lei, X.G. The Selenium Deficiency Disease Exudative Diathesis in Chicks Is Associated with Downregulation of Seven Common Selenoprotein Genes in Liver and Muscle-3. J. Nutr. 2011, 141, 1605-1610. [CrossRef] [PubMed]

13. Huang, J.-Q.; Ren, F.-Z.; Jiang, Y.-Y.; Lei, X. Characterization of selenoprotein M and its response to selenium deficiency in chicken brain. Biol. Trace Elem. Res. 2016, 170, 449-458. [CrossRef] [PubMed]

14. Huang, J.-Q.; Ren, F.-Z.; Jiang, Y.-Y.; Xiao, C.; Lei, X.G. Selenoproteins protect against avian nutritional muscular dystrophy by metabolizing peroxides and regulating redox/apoptotic signaling. Free Radic. Biol. Med. 2015, 83, 129-138. [CrossRef]

15. Scheuhammer, A.M. The chronic toxicity of aluminium, cadmium, mercury, and lead in birds: A review. Environ. Pollut. 1987, 46, 263-295.

16. Al-Waeli, A.; Zoidis, E.; Pappas, A.; Demiris, N.; Zervas, G.; Fegeros, K. The role of organic selenium in cadmium toxicity: Effects on broiler performance and health status. Animal 2013, 7, 386-393. [CrossRef] [PubMed]

17. Marettová, E.; Maretta, M.; Legáth, J.; Košutzká, E. The Retention of Cadmium and Selenium Influence in Fowl and Chickens of F 1 Generation. Biol. Trace Elem. Res. 2012, 147, 130-134. [CrossRef] [PubMed]

18. Liu, R.; Jia, T.; Cui, Y.; Lin, H.; Li, S. The Protective Effect of Selenium on the Chicken Pancreas against Cadmium Toxicity via Alleviating Oxidative Stress and Autophagy. Biol. Trace Elem. Res. 2018, 184, 240-246. [CrossRef]

19. Zhang, R.; Wang, Y.; Wang, C.; Zhao, P.; Liu, H.; Li, J.; Bao, J. Ameliorative Effects of Dietary Selenium Against Cadmium Toxicity Is Related to Changes in Trace Elements in Chicken Kidneys. Biol. Trace Elem. Res. 2017, 176, 391-400. [CrossRef]

20. Al-Waeli, A.; Pappas, A.; Zoidis, E.; Georgiou, C.; Fegeros, K.; Zervas, G. The role of selenium in cadmium toxicity: Interactions with essential and toxic elements. Br. Poult. Sci. 2012, 53, 817-827. [CrossRef]

21. Liu, S.; Xu, F.; Fu, J.; Li, S. Protective Roles of Selenium on Nitric Oxide and the Gene Expression of Inflammatory Cytokines Induced by Cadmium in Chicken Splenic Lymphocytes. Biol. Trace Elem. Res. 2015, 168, 252-260. [CrossRef] [PubMed]

22. Bulat, Z.P.; Djukić-Ćosić, D.; Maličević, Ž.; Bulat, P.; Matović, V. Zinc or magnesium supplementation modulates Cd intoxication in blood, kidney, spleen, and bone of rabbits. Biol. Trace Elem. Res. 2008, 124, 110-117. [CrossRef] [PubMed]

23. Papadomichelakis, G.; Zoidis, E.; Pappas, A.C.; Danezis, G.; Georgiou, C.A.; Fegeros, K. Dietary organic selenium addition and accumulation of toxic and essential trace elements in liver and meat of growing rabbits. Meat Sci. 2018, 145, 383-388. [CrossRef] [PubMed]

24. Risso-de Faverney, C.; Orsini, N.; De Sousa, G.; Rahmani, R. Cadmium-induced apoptosis through the mitochondrial pathway in rainbow trout hepatocytes: Involvement of oxidative stress. Aquat. Toxicol. 2004, 69, 247-258. [CrossRef] [PubMed] 
25. Pappas, A.; Zoidis, E.; Fegeros, K.; Surai, P.; Zervas, G. Relation of cadmium to other elements and the antioxidant system. In Cadmium in the Environment; Nova Science Publishers: New York, NY, USA, 2010; pp. 263-295.

26. Buchet, J.-P.; Lauwerys, R.; Roels, H.; Bernard, A.; Bruaux, P.; Claeys, F.; Ducoffre, G.; De Plaen, P.; Amery, A.; Lijnen, P. Renal effects of cadmium body burden of the general population. Lancet 1990, 336, 69-702. [CrossRef]

27. Kamaraju, S.; Ramasamy, K. Effect of cadmium chloride on glycogen content in gill, liver and kidney of edible exotic fish Hypophthalmichthys molitrix. Int. J. Curr. Res. 2011, 3, $53-57$.

28. Wang, X.; Bao, R.; Fu, J. The Antagonistic Effect of Selenium on Cadmium-Induced Damage and mRNA Levels of Selenoprotein Genes and Inflammatory Factors in Chicken Kidney Tissue. Biol. Trace Elem. Res. 2018, 181, 331-339. [CrossRef] [PubMed]

29. Kampa, M.; Castanas, E. Human health effects of air pollution. Environ. Pollut. 2008, 151, 362-367. [CrossRef]

30. Klaassen, C.D.; Amdur, M.O. Casarett and Doull's Toxicology: The Basic Science of Poisons; McGraw-Hill: New York, NY, USA, 2013; Volume 1236.

31. Huang, Y.; He, C.; Shen, C.; Guo, J.; Mubeen, S.; Yuana, J.; Yang, Z. Toxicity of cadmium and its health risks from leafy vegetable consumption. Food Funct. 2017, 8, 1373-1401.

32. Flora, G.; Gupta, D.; Tiwari, A. Toxicity of lead: A review with recent updates. Interdiscip. Toxicol. 2012, 5, 47-58. [CrossRef]

33. Dietert, R.R.; Piepenbrink, M.S. Lead and immune function. Crit. Rev. Toxicol. 2006, 36, 359-385. [CrossRef] [PubMed]

34. Mitra, P.; Sharma, S.; Purohit, P.; Sharma, P. Clinical and molecular aspects of lead toxicity: An update. Crit. Rev. Clin. Lab. Sci. 2017, 54, 506-528. [CrossRef] [PubMed]

35. Xing, M.; Jin, X.; Wang, J.; Shi, Q.; Cai, J.; Xu, S. The Antagonistic Effect of Selenium on Lead-Induced Immune Dysfunction via Recovery of Cytokine and Heat Shock Protein Expression in Chicken Neutrophils. Biol. Trace Elem. Res. 2018, 185, 162-169. [CrossRef] [PubMed]

36. Huang, H.; Wang, Y.; An, Y.; Tian, Y.; Li, S.; Teng, X. Selenium for the mitigation of toxicity induced by lead in chicken testes through regulating mRNA expressions of HSPs and selenoproteins. Environ. Sci. Pollut. Res. 2017, 24, 14312-14321. [CrossRef] [PubMed]

37. Gasparik, J.; Venglarcik, J.; Slamecka, J.; Kropil, R.; Smehyl, P.; Kopecky, J. Distribution of lead in selected organs and its effect on reproduction parameters of pheasants (Phasianus colchicus) after an experimental per oral administration. J. Environ. Sci. Health Part A Environ. Sci. Eng. 2012, 47, 1267-1271. [CrossRef]

38. Butkauskas, D.; Sruoga, A. Effect of lead and chromium on reproductive success of Japanese quail. Environ. Toxicol. Int. J. 2004, 19, 412-415. [CrossRef]

39. Lee, H.S.; Park, H.-W.; Song, W.-J.; Jeon, E.Y.; Bang, B.; Shim, E.-J.; Moon, H.-G.; Kim, Y.-K.; Kang, H.-R.; Min, K.-U. TNF- $\alpha$ enhance Th2 and Th17 immune responses regulating by IL23 during sensitization in asthma model. Cytokine 2016, 79, 23-30. [CrossRef]

40. de Andrés, M.C.; Takahashi, A.; Oreffo, R.O. Demethylation of an NF-kB enhancer element orchestrates iNOS induction in osteoarthritis and is associated with altered chondrocyte cell cycle. Osteoarthr. Cartil. 2016, 24, 1951-1960. [CrossRef]

41. Tan, S.; Chi, Q.; Liu, T.; Sun, Z.; Min, Y.; Zhang, Z.; Li, S. Alleviation mechanisms of selenium on cadmium-spiked neutrophil injury to chicken. Biol. Trace Elem. Res. 2017, 178, 301-309. [CrossRef]

42. Liu, L.-L.; Li, C.-M.; Zhang, Z.-W.; Zhang, J.-L.; Yao, H.-D.; Xu, S.-W. Protective effects of selenium on cadmium-induced brain damage in chickens. Biol. Trace Elem. Res. 2014, 158, 176-185. [CrossRef]

43. Låg, M.; Refsnes, M.; Lilleaas, E.M.; Holme, J.A.; Becher, R.; Schwarze, P.E. Role of mitogen activated protein kinases and protein kinase $\mathrm{C}$ in cadmium-induced apoptosis of primary epithelial lung cells. Toxicology 2005, 211, 253-264. [CrossRef] [PubMed]

44. Xu, F.; Liu, S.; Li, S. Effects of selenium and cadmium on changes in the gene expression of immune cytokines in chicken splenic lymphocytes. Biol. Trace Elem. Res. 2015, 165, 214-221. [CrossRef] [PubMed]

45. Zhang, R.; Yi, R.; Bi, Y.; Xing, L.; Bao, J.; Li, J. The effect of selenium on the Cd-induced apoptosis via NO-mediated mitochondrial apoptosis pathway in chicken liver. Biol. Trace Elem. Res. 2017, 178, 310-319. [CrossRef] [PubMed]

46. Chen, J.; Pan, T.; Wan, N.; Sun, Z.; Zhang, Z.; Li, S. Cadmium-induced endoplasmic reticulum stress in chicken neutrophils is alleviated by selenium. J. Inorg. Biochem. 2017, 170, 169-177. [CrossRef] [PubMed] 
47. Zhang, R.; Liu, Y.; Xing, L.; Zhao, N.; Zheng, Q.; Li, J.; Bao, J. The protective role of selenium against cadmium-induced hepatotoxicity in laying hens: Expression of Hsps and inflammation-related genes and modulation of elements homeostasis. Ecotoxicol. Environ. Saf. 2018, 159, 205-212. [CrossRef] [PubMed]

48. Chen, M.; Li, X.; Fan, R.; Yang, J.; Jin, X.; Hamid, S.; Xu, S. Cadmium induces BNIP3-dependent autophagy in chicken spleen by modulating miR-33-AMPK axis. Chemosphere 2018, 194, 396-402. [CrossRef]

49. Wang, S.; Xu, Z.; Yin, H.; Min, Y.; Li, S. Alleviation mechanisms of selenium on cadmium-spiked in chicken ovarian tissue: Perspectives from autophagy and energy metabolism. Biol. Trace Elem. Res. 2018, 186, 521-528. [CrossRef]

50. Amantana, A.; Vorachek, W.; Butler, J.; Costa, N.; Whanger, P. Effect of copper, zinc and cadmium on the promoter of selenoprotein $\mathrm{W}$ in glial and myoblast cells. J. Inorg. Biochem. 2002, 91, 356-362. [CrossRef]

51. Zhao, W.; Liu, W.; Chen, X.; Zhu, Y.; Zhang, Z.; Yao, H.; Xu, S. Four endoplasmic reticulum resident selenoproteins may be related to the protection of selenium against cadmium toxicity in chicken lymphocytes. Biol. Trace Elem. Res. 2014, 161, 328-333. [CrossRef]

52. Yao, H.; Fan, R.; Zhao, X.; Zhao, W.; Liu, W.; Yang, J.; Sattar, H.; Zhao, J.; Zhang, Z.; Xu, S. Selenoprotein W redox-regulated $\mathrm{Ca} 2+$ channels correlate with selenium deficiency-induced muscles $\mathrm{Ca} 2+$ leak. Oncotarget 2016, 7, 57618-57632. [CrossRef]

53. Liu, S.; Xu, F.-P.; Yang, Z.-J.; Li, M.; Min, Y.-H.; Li, S. Cadmium-induced injury and the ameliorative effects of selenium on chicken splenic lymphocytes: Mechanisms of oxidative stress and apoptosis. Biol. Trace Elem. Res. 2014, 160, 340-351. [CrossRef] [PubMed]

54. Chen, M.; Li, X.; Fan, R.; Cao, C.; Yao, H.; Xu, S. Selenium antagonizes cadmium-induced apoptosis in chicken spleen but not involving Nrf2-regulated antioxidant response. Ecotoxicol. Environ. Saf. 2017, 145, 503-510. [CrossRef] [PubMed]

55. Yao, H.-D.; Wu, Q.; Zhang, Z.-W.; Li, S.; Wang, X.-L.; Lei, X.-G.; Xu, S.-W. Selenoprotein W serves as an antioxidant in chicken myoblasts. Biochim. Biophys. Acta-Gen. Subj. 2013, 1830, 3112-3120. [CrossRef] [PubMed]

56. El-Sharaky, A.; Newairy, A.; Badreldeen, M.; Eweda, S.; Sheweita, S. Protective role of selenium against renal toxicity induced by cadmium in rats. Toxicology 2007, 235, 185-193. [CrossRef] [PubMed]

57. Messaoudi, I.; Banni, M.; Said, L.; Said, K.; Kerkeni, A. Involvement of selenoprotein P and GPx4 gene expression in cadmium-induced testicular pathophysiology in rat. Chem.-Biol. Interact. 2010, 188, 94-101. [CrossRef] [PubMed]

58. Surh, Y.-J.; Chun, K.-S.; Cha, H.-H.; Han, S.S.; Keum, Y.-S.; Park, K.-K.; Lee, S.S. Molecular mechanisms underlying chemopreventive activities of anti-inflammatory phytochemicals: Down-regulation of COX-2 and iNOS through suppression of NF-kB activation. Mutat. Res.Fundam. Mol. Mech. Mutagen. 2001, 480, 243-268. [CrossRef]

59. Speyer, C.L.; Neff, T.A.; Warner, R.L.; Guo, R.-F.; Sarma, J.V.; Riedemann, N.C.; Murphy, M.E.; Murphy, H.S.; Ward, P.A. Regulatory effects of iNOS on acute lung inflammatory responses in mice. Am. J. Pathol. 2003, 163, 2319-2328. [CrossRef]

60. Kanuri, G.; Spruss, A.; Wagnerberger, S.; Bischoff, S.C.; Bergheim, I. Role of tumor necrosis factor $\alpha$ (TNF $\alpha)$ in the onset of fructose-induced nonalcoholic fatty liver disease in mice. J. Nutr. Biochem. 2011, 22, 527-534. [CrossRef]

61. Sehnert, B.; Burkhardt, H.; Wessels, J.T.; Schröder, A.; May, M.J.; Vestweber, D.; Zwerina, J.; Warnatz, K.; Nimmerjahn, F.; Schett, G. NF-кB inhibitor targeted to activated endothelium demonstrates a critical role of endothelial NF-кB in immune-mediated diseases. Proc. Natl. Acad. Sci. USA 2013, 110, 16556-16561. [CrossRef]

62. Avadhesh, K.; Chauhan, R.S.; Singh, N.P. Effects of sub chronic lead intoxication on macrophage functions of chickens. J. Clin. Immunol. Immunopathol. Res. 2000, 2, 71-72.

63. Sun, G.X.; Chen, Y.; Liu, C.P.; Li, S.; Fu, J. Effect of Selenium Against Lead-Induced Damage on the Gene Expression of Heat Shock Proteins and Inflammatory Cytokines in Peripheral Blood Lymphocytes of Chickens. Biol. Trace Elem. Res. 2016, 172, 474-480. [CrossRef] [PubMed]

64. Liu, Q.; Lei, Z.; Huang, A.; Lu, Q.; Wang, X.; Ahmed, S.; Awais, I.; Yuan, Z. Mechanisms of the Testis Toxicity Induced by Chronic Exposure to Mequindox. Front. Pharmacol. 2017, 8, 679. [CrossRef] [PubMed] 
65. Jiao, X.; Yang, K.; An, Y.; Teng, X.; Teng, X. Alleviation of lead-induced oxidative stress and immune damage by selenium in chicken bursa of Fabricius. Environ. Sci. Pollut. Res. Int. 2017, 24, 7555-7564. [CrossRef] [PubMed]

66. Huang, H.; An, Y.; Jiao, W.; Wang, J.; Li, S.; Teng, X. CHOP/caspase-3 signal pathway involves in mitigative effect of selenium on lead-induced apoptosis via endoplasmic reticulum pathway in chicken testes. Environ. Sci. Pollut. Res. 2018, 25, 18838-18845. [CrossRef] [PubMed]

67. Wang, Y.; Wang, K.; Huang, H.; Gu, X.; Teng, X. Alleviative effect of selenium on inflammatory damage caused by lead via inhibiting inflammatory factors and heat shock proteins in chicken testes. Environ. Sci. Pollut. Res. 2017, 24, 13405-13413. [CrossRef]

68. Jin, X.; Xu, Z.; Zhao, X.; Chen, M.; Xu, S. The antagonistic effect of selenium on lead-induced apoptosis via mitochondrial dynamics pathway in the chicken kidney. Chemosphere 2017, 180, 259-266. [CrossRef] [PubMed]

69. Wang, X.; An, Y.; Jiao, W.; Zhang, Z.; Han, H.; Gu, X.; Teng, X. Selenium protects against lead-induced apoptosis via endoplasmic reticulum stress in chicken kidneys. Biol. Trace Elem. Res. 2018, 182, 354-363. [CrossRef]

70. Li, X.; Xing, M.; Chen, M.; Zhao, J.; Fan, R.; Zhao, X.; Cao, C.; Yang, J.; Zhang, Z.; Xu, S. Effects of selenium-lead interaction on the gene expression of inflammatory factors and selenoproteins in chicken neutrophils. Ecotoxicol. Environ. Saf. 2017, 139, 447-453. [CrossRef]

71. Zhao, D.; Zhang, X. Selenium Antagonizes the Lead-Induced Apoptosis of Chicken Splenic Lymphocytes In Vitro by Activating the PI3K/Akt Pathway. Biol. Trace Elem. Res. 2018, 182, 119-129. [CrossRef]

72. Zhu, Y.; Jiao, X.; An, Y.; Li, S.; Teng, X. Selenium against lead-induced apoptosis in chicken nervous tissues via mitochondrial pathway. Oncotarget 2017, 8, 108130. [CrossRef]

73. Liu, Y.; Jiao, X.; Teng, X.; Gu, X.; Teng, X. Antagonistic effect of selenium on lead-induced inflammatory injury through inhibiting the nuclear factor- $\mathrm{kB}$ signaling pathway and stimulating selenoproteins in chicken hearts. RSC Adv. 2017, 7, 24878-24884. [CrossRef]

74. Gao, H.; Liu, C.P.; Song, S.Q.; Fu, J. Effects of Dietary Selenium Against Lead Toxicity on mRNA Levels of 25 Selenoprotein Genes in the Cartilage Tissue of Broiler Chicken. Biol. Trace Elem. Res. 2016, 172, $234-241$. [CrossRef] [PubMed]

75. Cai, J.; Zhang, Y.; Yang, J.; Liu, Q.; Zhao, R.; Hamid, S.; Wang, H.; Xu, S.; Zhang, Z. Antagonistic effects of selenium against necroptosis injury via adiponectin-necrotic pathway induced by cadmium in heart of chicken. RSC Adv. 2017, 7, 44438-44446. [CrossRef]

76. Chen, X.; Zhu, Y.H.; Cheng, X.Y.; Zhang, Z.W.; Xu, S.W. The protection of selenium against cadmium-induced cytotoxicity via the heat shock protein pathway in chicken splenic lymphocytes. Molecules (Basel) 2012, 17, 14565-14572. [CrossRef] [PubMed]

77. St-Pierre, N.; Cobanov, B.; Schnitkey, G. Economic losses from heat stress by US livestock industries. J. Dairy Sci. 2003, 86, E52-E77. [CrossRef]

78. Daghir, N.J. Poultry Production in Hot Climates; Cabi: Wallingford, UK, 2008.

79. Mashaly, M.; Hendricks, G., 3rd; Kalama, M.; Gehad, A.; Abbas, A.; Patterson, P. Effect of heat stress on production parameters and immune responses of commercial laying hens. Poult. Sci. 2004, 83, 889-894. [CrossRef] [PubMed]

80. Lara, L.; Rostagno, M. Impact of heat stress on poultry production. Animals 2013, 3, 356-369. [CrossRef]

81. Sohail, M.U.; Ijaz, A.; Yousaf, M.S.; Ashraf, K.; Zaneb, H.; Aleem, M.; Rehman, H. Alleviation of cyclic heat stress in broilers by dietary supplementation of mannan-oligosaccharide and Lactobacillus-based probiotic: Dynamics of cortisol, thyroid hormones, cholesterol, C-reactive protein, and humoral immunity. Poult. Sci. 2010, 89, 1934-1938.

82. Novero, R.; Beck, M.; Gleaves, E.; Johnson, A.; Deshazer, J. Plasma progesterone, luteinizing hormone concentrations, and granulosa cell responsiveness in heat-stressed hens. Poult. Sci. 1991, 70, 2335-2339. [CrossRef]

83. Maak, S.; Melesse, A.; Schmidt, R.; Schneider, F.; Von Lengerken, G. Effect of long-term heat exposure on peripheral concentrations of heat shock protein 70 (Hsp70) and hormones in laying hens with different genotypes. Br. Poult. Sci. 2003, 44, 133-138. [CrossRef] [PubMed]

84. Rozenboim, I.; Tako, E.; Gal-Garber, O.; Proudman, J.; Uni, Z. The effect of heat stress on ovarian function of laying hens. Poult. Sci. 2007, 86, 1760-1765. [CrossRef] [PubMed] 
85. Zahraa, H.; Ghamdi, A. Effects of commutative heat stress on immunoresponses in broiler chickens reared in closed system. Int. J. Poult. Sci. 2008, 7, 964-968.

86. Syafwan, S.; Kwakkel, R.; Verstegen, M. Heat stress and feeding strategies in meat-type chickens. World's Poult. Sci. J. 2011, 67, 653-674. [CrossRef]

87. Quinteiro-Filho, W.M.; Ribeiro, A.; Ferraz-de-Paula, V.; Pinheiro, M.; Sakai, M.; Sá, L.R.M.D.; Ferreira, A.J.P.; Palermo-Neto, J. Heat stress impairs performance parameters, induces intestinal injury, and decreases macrophage activity in broiler chickens. Poult. Sci. 2010, 89, 1905-1914. [CrossRef] [PubMed]

88. Wang, R.R.; Pan, X.J.; Peng, Z.Q. Effects of heat exposure on muscle oxidation and protein functionalities of pectoralis majors in broilers. Poult. Sci. 2009, 88, 1078-1084. [CrossRef]

89. Sahin, K.; Kucuk, O. Zinc supplementation alleviates heat stress in laying Japanese quail. J. Nutr. 2003, 133, 2808-2811. [CrossRef] [PubMed]

90. Kelman, K.R.; Pannier, L.; Pethick, D.W.; Gardner, G.E. Selection for lean meat yield in lambs reduces indicators of oxidative metabolism in the longissimus muscle. Meat Sci. 2014, 96, 1058-1067. [CrossRef] [PubMed]

91. Lin, H.; Decuypere, E.; Buyse, J. Acute heat stress induces oxidative stress in broiler chickens. Comp. Biochem. Physiol. Part A Mol. Integr. Physiol. 2006, 144, 11-17. [CrossRef]

92. El-Kholy, M.S.; El-Hindawy, M.M.; Alagawany, M.; Abd El-Hack, M.E.; El-Sayed, S. Dietary Supplementation of Chromium Can Alleviate Negative Impacts of Heat Stress on Performance, Carcass Yield, and Some Blood Hematology and Chemistry Indices of Growing Japanese Quail. Biol. Trace Elem. Res. 2017, 179, 148-157. [CrossRef]

93. S. El-Kholy, M.; M. El-Hindawy, M.; Alagawany, M.; Abd El-Hack, M.; El-Sayed, S. Use of acetylsalicylic acid as an allostatic modulator in the diets of growing Japanese quails exposed to heat stress. J. Therm. Biol. 2018, 74, 6-13. [CrossRef] [PubMed]

94. Gabler, N.; Frouel, S.; Awati, A.; Owusu-Asiedu, A.; Amerah, A.; Patridge, G.; Dunshea, F. Betaine mitigates intestinal permeability in growing pigs induced by heat stress. In Proceedings of the Manipulating Pig Production XIV, Melbourne, Australia, 24-27 November 2013; Pluske, J.R., Pluske, J.M., Eds.; Australian Pig Science Association: Melbourne, Australia, 2013; Volume 85.

95. Adomako, K.; Habashy, W.; Milfort, M.; Fuller, A.; Rekaya, R.; Aggrey, S. Transcriptome analysis of genes in the protein biosynthesis and ubiquitin-proteosome pathways in meat-type chickens under heat stress. In Proceedings of the 25th World's Poultry Congress September, Beijing, China, 5-9 September 2016; pp. 5-9.

96. Gu, Z.T.; Li, L.; Wu, F.; Zhao, P.; Yang, H.; Liu, Y.S.; Geng, Y.; Zhao, M.; Su, L. Heat stress induced apoptosis is triggered by transcription-independent p53, $\mathrm{Ca}(2+)$ dyshomeostasis and the subsequent Bax mitochondrial translocation. Sci. Rep. 2015, 5, 11497. [CrossRef] [PubMed]

97. Li, L.; Tan, H.; Gu, Z.; Liu, Z.; Geng, Y.; Liu, Y.; Tong, H.; Tang, Y.; Qiu, J.; Su, L. Heat stress induces apoptosis through a $\mathrm{Ca}(2)(+)$-mediated mitochondrial apoptotic pathway in human umbilical vein endothelial cells. PLoS ONE 2014, 9, e111083. [CrossRef] [PubMed]

98. Williams, C.; Kronfeld, D.; Hess, T.; Saker, K.; Waldron, J.; Crandell, K.; Hoffman, R.; Harris, P. Antioxidant supplementation and subsequent oxidative stress of horses during an 80-km endurance race. J. Anim. Sci. 2004, 82, 588-594. [CrossRef] [PubMed]

99. Lin, H.; De Vos, D.; Decuypere, E.; Buyse, J. Dynamic changes in parameters of redox balance after mild heat stress in aged laying hens (Gallus gallus domesticus). Comp. Biochem. Physiol. Part C Toxicol. Pharmacol. 2008, 147, 30-35. [CrossRef] [PubMed]

100. Lambert, G.P. Stress-induced gastrointestinal barrier dysfunction and its inflammatory effects. J. Anim. Sci. 2009, 87, E101-E108. [CrossRef] [PubMed]

101. Skrivan, M.; Dlouha, G.; Mašata, O.; Ševčíková, S. Effect of dietary selenium on lipid oxidation, selenium and vitamin E content in the meat of broiler chickens. Czech. J. Anim. Sci. 2008, 53, 306-311. [CrossRef]

102. Khan, A.Z.; Kumbhar, S.; Hamid, M.; Afzal, S.; Parveen, F.; Liu, Y.; Shu, H.; Mengistu, B.M.; Huang, K. Effects of Selenium-Enriched Probiotics on Heart Lesions by Influencing the mRNA Expressions of Selenoproteins and Heat Shock Proteins in Heat Stressed Broiler Chickens. Pak. Vet. J. 2016, 36, 460-464.

103. Özdemir, D.; Akşit, M.; Özkan, S.; Yalçin, S.; Metin, K. Effects of Temperature During Rearing and Crating on Stress Parameters and Meat Quality of Broilers. Poult. Sci. 2006, 85, 1867-1874.

104. Chan, J.T.; Omana, D.A.; Betti, M. Functional and rheological properties of proteins in frozen turkey breast meat with different ultimate pH. Poult. Sci. 2011, 90, 1112-1123. [CrossRef] 
105. Slawinska, A.; Hsieh, J.C.; Schmidt, C.J.; Lamont, S.J. Heat Stress and Lipopolysaccharide Stimulation of Chicken Macrophage-Like Cell Line Activates Expression of Distinct Sets of Genes. PLoS ONE 2016, 11, e0164575. [CrossRef] [PubMed]

106. Xu, D.; Li, W.; Huang, Y.; He, J.; Tian, Y. The effect of selenium and polysaccharide of Atractylodes macrocephala Koidz. (PAMK) on immune response in chicken spleen under heat stress. Biol. Trace Elem. Res. 2014, 160, 232-237. [CrossRef] [PubMed]

107. Yao, Y.; Lu, Q.; Hu, Z.; Yu, Y.; Chen, Q.; Wang, Q.K. A non-canonical pathway regulates ER stress signaling and blocks ER stress-induced apoptosis and heart failure. Nat. Commun. 2017, 8, 133. [CrossRef] [PubMed]

108. Xu, D.; Li, W.; Li, B.; Tian, Y.; Huang, Y. The effect of selenium and polysaccharide of Atractylodes macrocephala Koidz.(PAMK) on endoplasmic reticulum stress and apoptosis in chicken spleen induced by heat stress. RSC Adv. 2017, 7, 7519-7525. [CrossRef]

109. Sumimoto, H. Structure, regulation and evolution of Nox-family NADPH oxidases that produce reactive oxygen species. FEBS J. 2008, 275, 3249-3277.

110. Habashy, W.S.; Milfort, M.C.; Rekaya, R.; Aggrey, S.E. Expression of genes that encode cellular oxidant/antioxidant systems are affected by heat stress. Mol. Biol. Rep. 2018, 45, 389-394. [CrossRef]

111. Banfi, B.; Clark, R.A.; Steger, K.; Krause, K.H. Two novel proteins activate superoxide generation by the NADPH oxidase NOX1. J. Biol. Chem. 2003, 278, 3510-3513. [CrossRef]

112. Panday, A.; Sahoo, M.K.; Osorio, D.; Batra, S. NADPH oxidases: An overview from structure to innate immunity-associated pathologies. Cell. Mol. Immunol. 2015, 12, 5-23. [CrossRef]

113. Ueno, N.; Takeya, R.; Miyano, K.; Kikuchi, H.; Sumimoto, H. The NADPH oxidase Nox3 constitutively produces superoxide in a p22phox-dependent manner: Its regulation by oxidase organizers and activators. J. Biol. Chem. 2005, 280, 23328-23339. [CrossRef]

114. Geiszt, M.; Witta, J.; Baffi, J.; Lekstrom, K.; Leto, T.L. Dual oxidases represent novel hydrogen peroxide sources supporting mucosal surface host defense. Off. Publ. Fed. Am. Soc. Exp. Biol. 2003, 17, 1502-1504. [CrossRef]

115. Bánfi, B.; Tirone, F.; Durussel, I.; Knisz, J.; Moskwa, P.; Molnár, G.Z.; Krause, K.-H.; Cox, J.A. Mechanism of Ca2+ activation of the NADPH oxidase 5 (NOX5). J. Biol. Chem. 2004, 279, 18583-18591.

116. Banfi, B.; Molnar, G.; Maturana, A.; Steger, K.; Hegedus, B.; Demaurex, N.; Krause, K.H. A Ca(2+)-activated NADPH oxidase in testis, spleen, and lymph nodes. J. Biol. Chem. 2001, 276, 37594-37601. [CrossRef] [PubMed]

117. Lin, H.; Du, R.; Gu, X.H.; Li, F.C.; Zhang, Z.Y. A Study on the Plasma Biochemical Indices of Heat-Stressed Broilers. Asian-Australas. J. Anim. Sci. 2000, 13, 1210-1218. [CrossRef]

118. Hu, Y.; Rosen, D.G.; Zhou, Y.; Feng, L.; Yang, G.; Liu, J.; Huang, P. Mitochondrial manganese-superoxide dismutase expression in ovarian cancer: Role in cell proliferation and response to oxidative stress. J. Biol. Chem. 2005, 280, 39485-39492. [CrossRef] [PubMed]

119. Sedeek, M.; Nasrallah, R.; Touyz, R.M.; Hebert, R.L. NADPH oxidases, reactive oxygen species, and the kidney: Friend and foe. J. Am. Soc. Nephrol. 2013, 24, 1512-1518. [CrossRef]

120. Kim, H.J.; Yun, J.; Lee, J.; Hong, H.; Jeong, J.; Kim, E.; Bae, Y.S.; Lee, K.J. SUMO1 attenuates stress-induced ROS generation by inhibiting NADPH oxidase 2. Biochem. Biophys. Res. Commun. 2011, 410, 555-562. [CrossRef]

121. Zelko, I.N.; Mariani, T.J.; Folz, R.J. Superoxide dismutase multigene family: A comparison of the CuZn-SOD (SOD1), Mn-SOD (SOD2), and EC-SOD (SOD3) gene structures, evolution, and expression. Free Radic. Biol. Med. 2002, 33, 337-349. [CrossRef]

122. Schafer, F.Q.; Buettner, G.R. Redox environment of the cell as viewed through the redox state of the glutathione disulfide/glutathione couple. Free Radic. Biol. Med. 2001, 30, 1191-1212. [CrossRef]

123. Azad, M.A.; Kikusato, M.; Maekawa, T.; Shirakawa, H.; Toyomizu, M. Metabolic characteristics and oxidative damage to skeletal muscle in broiler chickens exposed to chronic heat stress. Comp. Biochem. Physiol. Part A Mol. Integr. Physiol. 2010, 155, 401-406. [CrossRef]

124. Min, J.Y.; Lim, S.O.; Jung, G. Downregulation of catalase by reactive oxygen species via hypermethylation of CpG island II on the catalase promoter. FEBS Lett. 2010, 584, 2427-2432. [CrossRef]

125. Quan, X.; Lim, S.O.; Jung, G. Reactive oxygen species downregulate catalase expression via methylation of a CpG island in the Oct-1 promoter. FEBS Lett. 2011, 585, 3436-3441. [CrossRef] [PubMed] 
126. Brigelius-Flohé, R.; Maiorino, M. Glutathione peroxidases. Biochim. Biophys. Acta 2013, 1830, 3289-3303. [CrossRef] [PubMed]

127. Niu, W.-N.; Yadav, P.K.; Adamec, J.; Banerjee, R. S-glutathionylation enhances human cystathionine $\beta$-synthase activity under oxidative stress conditions. Antioxid. Redox Signal. 2015, 22, 350-361. [CrossRef] [PubMed]

128. Habashy, W.S.; Milfort, M.C.; Adomako, K.; Attia, Y.A.; Rekaya, R.; Aggrey, S.E. Effect of heat stress on amino acid digestibility and transporters in meat-type chickens. Poult. Sci. 2017, 96, 2312-2319. [CrossRef] [PubMed]

129. Eriksson, S.; Prigge, J.R.; Talago, E.A.; Arnér, E.S.J.; Schmidt, E.E. Dietary methionine can sustain cytosolic redox homeostasis in the mouse liver. Nat. Commun. 2015, 6, 6479. [CrossRef] [PubMed]

130. Venugopal, R.; Jaiswal, A.K. Nrf1 and Nrf2 positively and c-Fos and Fra1 negatively regulate the human antioxidant response element-mediated expression of $\mathrm{NAD}(\mathrm{P}) \mathrm{H}$ :quinone oxidoreductase1 gene. Proc. Natl. Acad. Sci. USA 1996, 93, 14960-14965. [CrossRef] [PubMed]

131. Cheng, J.Z.; Sharma, R.; Yang, Y.; Singhal, S.S.; Sharma, A.; Saini, M.K.; Singh, S.V.; Zimniak, P.; Awasthi, S.; Awasthi, Y.C. Accelerated metabolism and exclusion of 4-hydroxynonenal through induction of RLIP76 and hGST5.8 is an early adaptive response of cells to heat and oxidative stress. J. Biol. Chem. 2001, 276, 41213-41223. [CrossRef] [PubMed]

132. Li, J.; Calkins, M.J.; Johnson, D.A.; Johnson, J.A. Role of Nrf2-dependent ARE-driven antioxidant pathway in neuroprotection. Methods Mol. Biol. (Clifton, N.J.) 2007, 399, 67-78.

133. Al-Zghoul, M.B.; Sukker, H.; Ababneh, M.M. Effect of thermal manipulation of broilers embryos on the response to heat-induced oxidative stress. Poult. Sci. 2019, 98, 991-1001. [CrossRef]

134. Kumbhar, S.; Khan, A.Z.; Parveen, F.; Nizamani, Z.A.; Siyal, F.A.; El-Hack, M.E.A.; Gan, F.; Liu, Y.; Hamid, M.; Nido, S.A.; et al. Impacts of selenium and vitamin E supplementation on mRNA of heat shock proteins, selenoproteins and antioxidants in broilers exposed to high temperature. AMB Express 2018, 8, 112. [CrossRef]

135. Shakeri, M.; Cottrell, J.J.; Wilkinson, S.; Ringuet, M.; Furness, J.B.; Dunshea, F.R. Betaine and Antioxidants Improve Growth Performance, Breast Muscle Development and Ameliorate Thermoregulatory Responses to Cyclic Heat Exposure in Broiler Chickens. Animals 2018, 8, 162. [CrossRef] [PubMed]

136. Khan, A.Z.; Kumbhar, S.; Liu, Y.; Hamid, M.; Pan, C.; Nido, S.A.; Parveen, F.; Huang, K. Dietary Supplementation of Selenium-Enriched Probiotics Enhances Meat Quality of Broiler Chickens (Gallus gallus domesticus) Raised Under High Ambient Temperature. Biol. Trace Elem. Res. 2018, 182, 328-338. [CrossRef] [PubMed]

137. Safdari-Rostamabad, M.; Hosseini-Vashan, S.J.; Perai, A.H.; Sarir, H. Nanoselenium Supplementation of Heat-Stressed Broilers: Effects on Performance, Carcass Characteristics, Blood Metabolites, Immune Response, Antioxidant Status, and Jejunal Morphology. Biol. Trace Elem. Res. 2017, 178, 105-116. [CrossRef] [PubMed]

138. El-Hack, M.E.A.; Mahrose, K.; Askar, A.A.; Alagawany, M.; Arif, M.; Saeed, M.; Abbasi, F.; Soomro, R.N.; Siyal, F.A.; Chaudhry, M.T. Single and combined impacts of vitamin A and selenium in diet on productive performance, egg quality, and some blood parameters of laying hens during hot season. Biol. Trace Elem. Res. 2017, 177, 169-179. [CrossRef] [PubMed]

139. Abd El-Hack, M.E.; Mahrose, K.; Arif, M.; Chaudhry, M.T.; Saadeldin, I.M.; Saeed, M.; Soomro, R.N.; Abbasi, I.H.; Rehman, Z.U. Alleviating the environmental heat burden on laying hens by feeding on diets enriched with certain antioxidants (vitamin E and selenium) individually or combined. Environ. Sci. Pollut. Res. Int. 2017, 24, 10708-10717. [CrossRef] [PubMed]

140. Organic Forms of Zinc, Selenium and Chromium on Performance, Anti-Oxidant and Immune Responses in Broiler Chicken Reared in Tropical Summer. Biol. Trace. Elem. Res. 2016, 172, 511-520. [CrossRef]

141. Habibian, M.; Ghazi, S.; Moeini, M.M. Effects of Dietary Selenium and Vitamin E on Growth Performance, Meat Yield, and Selenium Content and Lipid Oxidation of Breast Meat of Broilers Reared Under Heat Stress. Biol. Trace Elem. Res. 2016, 169, 142-152. [CrossRef]

142. Xu, D.; Tian, Y. Selenium and Polysaccharides of Atractylodes macrocephala Koidz Play Different Roles in Improving the Immune Response Induced by Heat Stress in Chickens. Biol. Trace Elem. Res. 2015, 168, 235-241. [CrossRef] 
143. Habibian, M.; Ghazi, S.; Moeini, M.M.; Abdolmohammadi, A. Effects of dietary selenium and vitamin E on immune response and biological blood parameters of broilers reared under thermoneutral or heat stress conditions. Int. J. Biometeorol. 2014, 58,741-752. [CrossRef]

144. Liao, X.; Lu, L.; Li, S.; Liu, S.; Zhang, L.; Wang, G.; Li, A.; Luo, X. Effects of selenium source and level on growth performance, tissue selenium concentrations, antioxidation, and immune functions of heat-stressed broilers. Biol. Trace Elem. Res. 2012, 150, 158-165. [CrossRef]

145. Ghazi Harsini, S.; Habibiyan, M.; Moeini, M.M.; Abdolmohammadi, A.R. Effects of dietary selenium, vitamin $\mathrm{E}$, and their combination on growth, serum metabolites, and antioxidant defense system in skeletal muscle of broilers under heat stress. Biol. Trace Elem. Res. 2012, 148, 322-330. [CrossRef] [PubMed]

146. Zeinali, A.; Kermanshahi, H.; Riasi, A.; Farhangfar, H.; Sarir, H.; Ziaie, H. Effects of sodium selenite and turmeric powder on thyroid hormones and plasma lipids of broiler chickens reared under heat stress condition. Glob. Vet. 2011, 6, 237-240.

147. Rey, A.I.; López-Bote, C.J.; Litta, G. Effects of dietary vitamin E (DL- $\alpha$-tocopheryl acetate) and vitamin C combination on piglets oxidative status and immune response at weaning. J. Anim. Feed Sci. 2017, 26, 226-235. [CrossRef]

148. Traber, M.G.; Atkinson, J. Vitamin E, antioxidant and nothing more. Free Radic. Biol. Med. 2007, 43, 4-15.

149. Gao, J.; Lin, H.; Wang, X.J.; Song, Z.G.; Jiao, H.C. Vitamin E supplementation alleviates the oxidative stress induced by dexamethasone treatment and improves meat quality in broiler chickens. Poult. Sci. 2010, 89, 318-327. [CrossRef] [PubMed]

150. Sahin, K.; Kucuk, O. Effects of vitamin C and vitamin E on performance, digestion of nutrients and carcass characteristics of Japanese quails reared under chronic heat stress (34 degrees C). J. Anim. Physiol. Anim. Nutr. 2001, 85, 335-341. [CrossRef]

151. Hosseini-Mansoub, N.; Chekani-Azar, S.; Tehrani, A.; Lotfi, A.; Manesh, M. Influence of dietary vitamin E and zinc on performance, oxidative stability and some blood measures of broiler chickens reared under heat stress ( $\left.35^{\circ} \mathrm{C}\right)$. J. Agrobiol. 2010, 27, 103-110. [CrossRef]

152. Zoidis, E.; Seremelis, I.; Kontopoulos, N.; Danezis, G.P. Selenium-Dependent Antioxidant Enzymes: Actions and Properties of Selenoproteins. Antioxidants (Basel) 2018, 7, E66. [CrossRef]

153. Hu, C.H.; Li, Y.L.; Xiong, L.; Zhang, H.M.; Song, J.; Xia, M.S. Comparative effects of nano elemental selenium and sodium selenite on selenium retention in broiler chickens. Anim. Feed Sci. Technol. 2012, 177, 204-210. [CrossRef]

154. Rao, S.V.; Prakash, B.; Raju, M.V.; Panda, A.K.; Poonam, S.; Murthy, O.K. Effect of supplementing organic selenium on performance, carcass traits, oxidative parameters and immune responses in commercial broiler chickens. Asian-Australas. J. Anim. Sci. 2013, 26, 247-252. [CrossRef] 